\title{
Communication
}

\section{New access to the synthesis of 1,1,4,4-tetracyanobuta-1,3-diene-based push-pull chromophores using tetracyanoethylene oxide via [3+2] cycloaddition-ring opening reactions}

Arif Hassan Dar, ${ }^{\mathrm{a}}$ Vijayendran Gowri, ${ }^{\mathrm{a}}$ Neethu K. M, ${ }^{\mathrm{a}}$ Govindasamy Jayamurugan ${ }^{\mathrm{a}, *}$ anstitute of Nano Science and Technology, Mohali-160062, Punjab, India.

*Corresponding Author Email: jayamurugan@inst.ac.in.

Keywords: tetracyanoethylene oxide, [3+2] cycloaddition, push-pull chromophores, 1,1,4,4tetracyanobuta-1,3-diene, [2+2] cycloaddition-retroelectrocyclization (CA-RE) reaction

\begin{abstract}
Herein we report a new way to access the synthesis of established invaluable pushpull chromophores based on 1,1,4,4-tetracyanobuta-1,3-dienes (TCBDs) using tetracyanoethylene oxide (TCNEO) upon reaction with alkynes substituted with an electrondonating group (EDG) via [3+2] cycloaddition (CA) followed by ring-opening $(\mathrm{RO})$ reactions. Further, we uncovered that the facile [3+2] CA-RO reaction under simpler reaction condition is possible due to the presence of EDG group, otherwise, even the formation of $[3+2]$ cycloadduct without EDG requires harsher condition and does not lead to TCBD as reported earlier in 1965 by Linn and Benson.
\end{abstract}

\section{Introduction}

The continuous generation of new organic push-pull chromophores has overwhelmed researchers from across the globe for about a past decade. Because of their immense applications in material fabrications, ${ }^{1}$ designing soft molecular device-optoelectronics, ${ }^{2}$ as fluorescence sensors, ${ }^{3}$ in bio-imaging, ${ }^{4}$ sensitizer in dye-sensitized solar cells, ${ }^{5}$ piezochromic materials, ${ }^{6}$ frequency-upconverted lasing, ${ }^{7}$ and photorefractive organic materials, ${ }^{8}$ etc. The exciting features of all the chromophores arise due to their encounter with the UV/Vis/NIRradiations. ${ }^{9}$ Interaction of organic push-pull chromophores with light can be easily tuned upon modulating the design of the donor and acceptor groups. This is feasible primarily because of the control by the donor and acceptor groups over the intramolecular charge transfer (ICT) process. Even small structural variation in donor- and acceptor-parts of push-pull chromophores bring a complete transformation in the properties of molecules. ${ }^{10}$ Cyano $(\mathrm{CN})$ 
group as an acceptor and amines as the donor has secured a prominent place owing to their strong push-pull nature. Synthetic methodology for exploring new acceptors and donors in the push-pull systems is possible with ease thanks to the well-established method pioneered by Diederich and co-workers based on the formal [2+2] cycloaddition-retroelectrocyclization $(\mathrm{CA}-\mathrm{RE})$ reaction between alkynes substituted with an electron-donating group (EDG) and electron-deficient olefin yielding EDG-substituted 1,1,4,4-tetracyanobuta-1,3-dienes (Figure 1a). ${ }^{11}$ The click-type [2+2] $\mathrm{CA}-\mathrm{RE}$ is a robust method for the preparation of nonplanar, $\pi$ conjugated, donor-acceptor (D-A) chromophores that exhibit intense intramolecular chargetransfer (CT) bands with lower energy. ${ }^{12}$ Some of them have found applications in devices for all-optical switching, ${ }^{2 a}$ organic field-effect transistor, ${ }^{13}$ light-emitting diodes, ${ }^{14}$ holetransporting materials in solar cell, ${ }^{15}$ and has also shown remarkable third-order nonlinear optical properties. $^{9 b}$

In general, the previous works reported on the synthesis of TCBDs based push-pull chromophores have mostly changed the donor moiety on the alkyne part, such as metal ylides, ${ }^{16}$ thiophenes, ${ }^{17}$ amines, ${ }^{11}$ ferrocene and TTF,${ }^{18}$ azulene,${ }^{19}$ pyrroles,${ }^{20}$ carbazole,${ }^{21}$ ynamide,${ }^{22}$ and recently urea. ${ }^{23}$ Whereas, in the case of the acceptor part, $\mathrm{CN}$ derivatives especially tetracyanoethene (TCNE) has been predominantly used as benchmark starting material. ${ }^{11 \mathrm{c}}$ Though another functional group such as carboxylic ester group has been used as acceptor but they act as a mild accepting unit and show less reactivity. ${ }^{24}$ To expand the chemical space for TCBD based push-pull chromophores, it is imperative to look for more tools to synthesize TCBDs apart from the conventional [2+2] CA-RE reaction as the only choice.

We envisaged exploring tetracyanoethylene oxide $(\mathrm{TCNEO}, \mathbf{1})$ as an alternative to TCNE because the oxirane ring would bring completely different reaction pathways. Further, it is also commercially available and easy to prepare on a large scale. ${ }^{25}$ In 1965 , it has been reported by Linn and Benson that TCNEO undergoes [3+2] cycloaddition (CA) with alkenes as well as alkynes to provide the corresponding cycloadducts of tetracyanotetrahydrofuran and tetracyanodihydrofuran (TCDHF) derivatives, respectively (Figure 1b). ${ }^{26}$ This cycloaddition reaction occurs by the temperature $\left(\geq 100{ }^{\circ} \mathrm{C}\right)$ assisted formation of carbonyl ylide due to the cleavage of the $\mathrm{C}-\mathrm{C}$ bond of the epoxide ring of TCNEO.${ }^{27}$ Recently, this chemistry has been successfully applied to fabricate graphene-TCNEO adduct and has been found to manipulate the electronic properties of graphene. ${ }^{28}$ 
a. 1,1,4,4-tetracyanobuta-1,3-dienes (TCBDs) via [2+2] CA-RE reactions between EDG-alkynes and TCNE by Diederich \& co-workers ${ }^{11}$

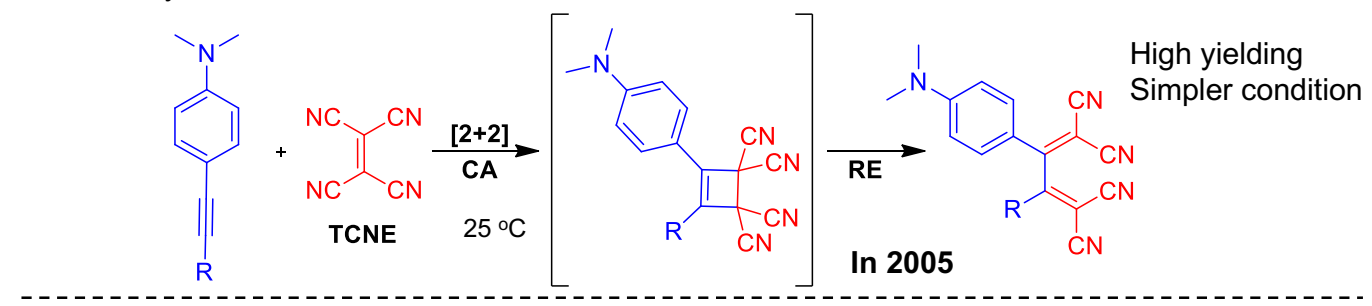

b. Tetracyanodihydrofuran adducts via [3+2] CA reaction between EDG-free alkyne and TCNEO by Linn and Benson ${ }^{26}$

Moderate yield

Harsher condition

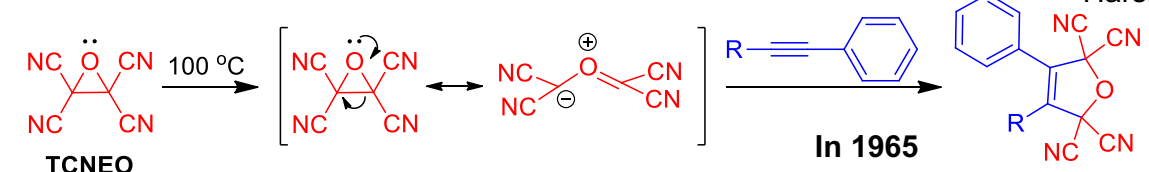

TCNEO

c. This work: TCBDs via [3+2] CA-RO reactions between EDG-alkynes and TCNEO
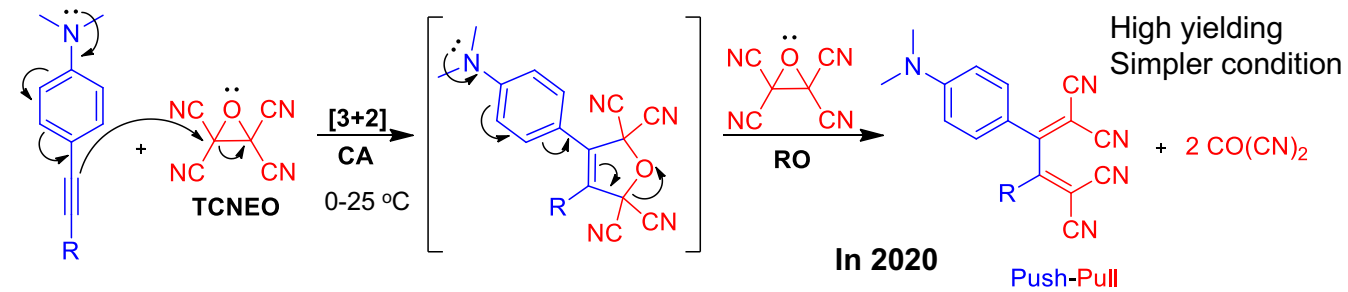

Figure 1. a) Push-pull TCBDs synthesis from EDG-alkynes and TCNE using formal "click"type [2+2] CA-RE reaction. ${ }^{11}$ b) [3+2] CA reaction between EDG-free alkynes and TCNEO providing stable tetracyanodihydrofurans. ${ }^{26} \mathrm{c}$ ) Push-pull TCBDs synthesis from EDG-alkyne and TCNEO via [3+2] CA-RO reaction.

However, it should be noted that the previously reported TCNEO and alkynes having no EDG gave exclusively TCDHF derivatives which were found to be very stable (Figure $1 b$ ). ${ }^{26}$ We hypothesized that incorporating the EDG group in the alkyne part would lead to subsequent ring-opening reactions as indicated in Figure 1c, thus possible to obtain some interesting new and useful products, for example, TCBD. With this hypothesis, we started to explore TCNEO as a potential precursor for the organic acceptor to undergo [3+2] CA reaction with electronrich alkynes such as $N, N^{\prime}$-dimethylamino (DMA)-substituted phenylacetylenes and the results are presented herein.

\section{Results and Discussion}

Initially, we investigated the reactivity of TCNEO with mono-substituted alkyne such as 4ethynyl- $N, N^{\prime}$-dimethylaniline $\mathbf{1}$ and explored its synthetic paths under different solvents and temperatures (Table 1). As we wish to check and identify whether the more useful TCBD 2 
would form under this condition, an authentic sample was prepared according to the literature procedure and compared. ${ }^{11 \mathrm{~b}}$ First, the reaction was conducted in $\mathrm{CH}_{2} \mathrm{Cl}_{2}$ at ambient condition (entries 1-3, Table 1), as indicated by the thin-layer chromatography (TLC) that the reaction occurred even without heating and showed not so clean with multiple spots (Figures S1-S3, Supporting Information (SI)). We were pleased to see that a trace amount of purple color spot appeared and matched with the authentic sample. This suggests that unlike the EDG-free alkyne which gives the stable [3+2] cycloadduct of TCDHF derivatives, ${ }^{26}$ this adduct with EDG undergoes further reaction paths leading to a complex mixture of products.

Table 1. Optimization studies for mono-substituted alkyne with $\mathrm{TCNEO}^{a}$

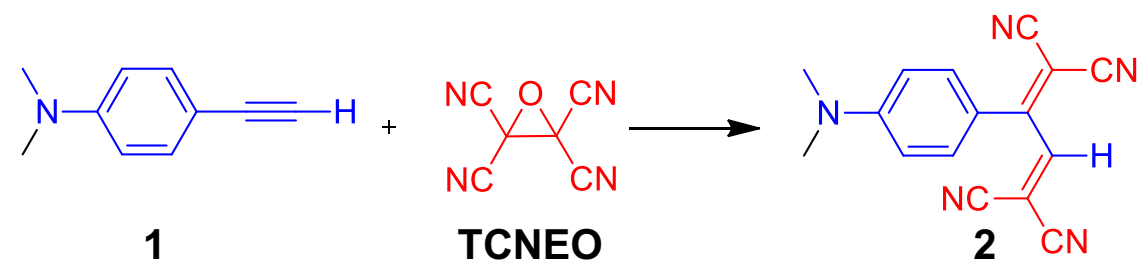

\begin{tabular}{llllll}
\hline entry & $\begin{array}{l}\text { TCNEO } \\
\text { equiv }\end{array}$ & $\begin{array}{l}\text { Temp } \\
\left({ }^{\mathbf{0}} \mathbf{C}\right)\end{array}$ & $\begin{array}{l}\text { Solvent } \\
\text { Additive }\end{array}$ & $\begin{array}{l}\text { TCBD 2 } \\
\text { Yield (\%) }\end{array}$ \\
\hline 1 & 1 & 25 & $\mathrm{CH}_{2} \mathrm{Cl}_{2}$ & none & trace \\
2 & 2 & 25 & $\mathrm{CH}_{2} \mathrm{Cl}_{2}$ & none & 10 \\
3 & 2 & 0 & $\mathrm{CH}_{2} \mathrm{Cl}_{2}$ & none & 5 \\
4 & 2 & 25 & $\mathrm{CH}_{3} \mathrm{CN}$ & none & 3 \\
5 & 1 & 60 & $\mathrm{CH}_{3} \mathrm{CN}$ & none & 2 \\
6 & 2 & 25 & $\mathrm{CH}_{2} \mathrm{Cl}$ & $\mathrm{LiClO}_{4}$ & Complex mixture \\
7 & 2 & 0 & $\mathrm{CH}_{3} \mathrm{CN}$ & $\mathrm{LiClO}_{4}$ & Complex mixture \\
8 & 2 & 60 & $\mathrm{CH}_{3} \mathrm{CN}$ & $\mathrm{LiClO}_{4}$ & Complex mixture \\
\hline
\end{tabular}

${ }^{a}$ Reactions were carried out on a $0.1 \mathrm{mmol}$ scale.

${ }^{b}$ Isolated yield.

Further, to improve the yield of TCBD 2 instead of an equimolar (equiv) amount of TCNEO, 2 equiv was reacted and found significant product formation of TCBD up to $10 \%$ yield (entries 2-3, Table 1). Changing the solvent from non-polar to polar and also the high temperature resulted in a low yield of TCBD 2. It has been reported by Diederich et al. that additive such as $\mathrm{LiClO}_{4}$ assists similar reactions like [3+2] cycloaddition-rearrangement and sometimes different reactivity. ${ }^{29,24 \mathrm{~b}}$ The addition of Lewis acid $\mathrm{LiClO}_{4}$ also did not improve the reaction and resulted in a more complex reaction mixture. Various attempts to improve the 
yield of TCBD were failed including changing the strong EDG $\left(-\mathrm{NMe}_{2}\right)$ into weaker EDG ($\mathrm{OMe}$ ) group such as 4-ethynyl anisole, though the TCNEO consumption occurs at high temperature and gave complex mixture. We infer that the over-reactions could be ascribed to the unsubstituted dicyanovinyl group in the 2-substituted 1,1,4,4-tetracyanobuta-1,3-dienes over 2,3-disubstituted 1,1,4,4-tetracyanobuta-1,3-dienes which is not stabilized by the EDG group. ${ }^{30}$

Hence, we turned our attention to synthesize bis-DMA-substituted alkynes $\mathbf{3}$ and $\mathbf{5}$ derivatives to further investigate its effect on TCNEO and possible generation of TCBD chromophores (Scheme 1). While using compounds $\mathbf{3}$ and $\mathbf{5}$ as donor alkynes and two equiv of TCNEO, we had observed the almost complete transformation of alkynes into the corresponding TCBDs 4 and $\mathbf{6}$ with a yield of 90 and 95\%, respectively without the use of any additives.

a)
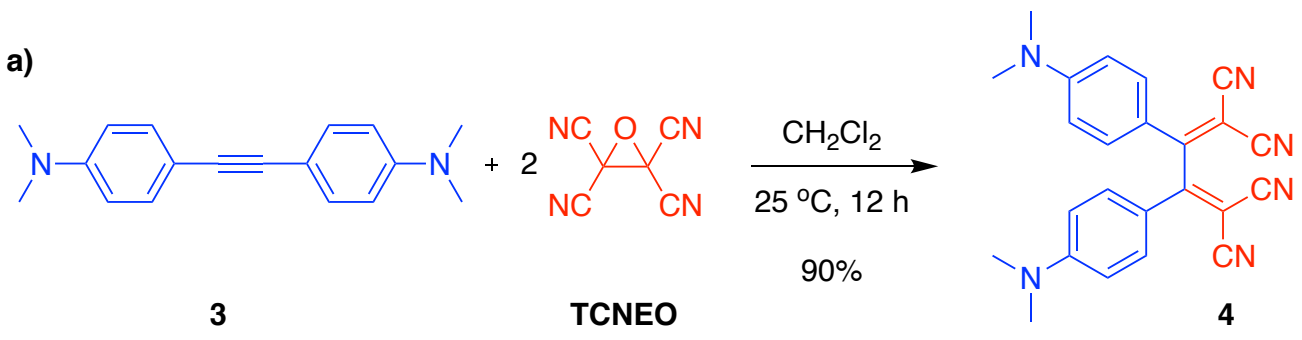

b)
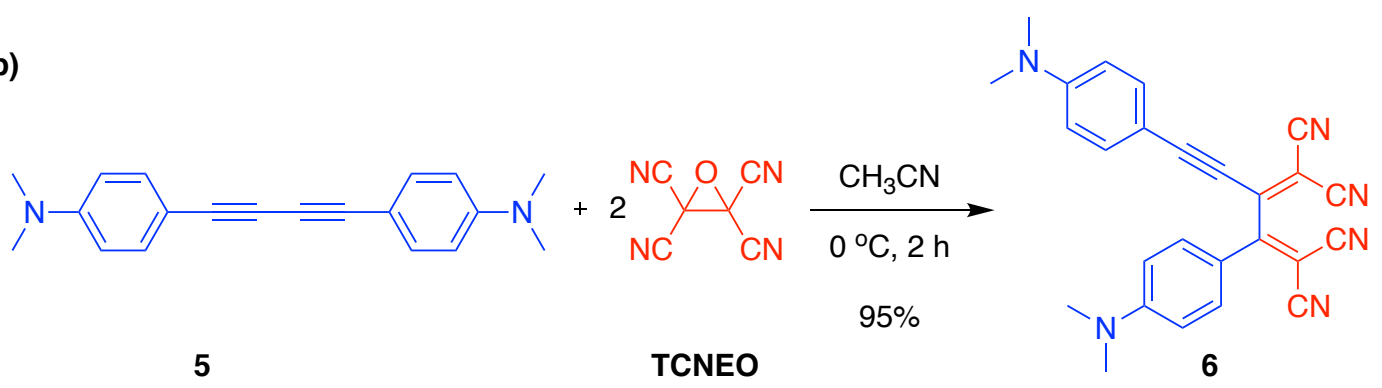

Scheme 1. Synthesis of 2,3-disubstituted TCBDs using TCNEO and bis-substituted alkynes via [3+2] CA followed by RO reactions.

The following observations were noticed upon screening for the best conditions. Regardless of TCNEO equivalents, only the TCBD products were formed and no [3+2] cycloadduct of tetracyanodihydrofuran was observed by TLC. Also, we found that 2 equiv of TCNEO was the optimum amount for the formation of TCBD products. Further, increasing more equiv of TCNEO did not significantly improve the yield. While chlorinated solvent $\mathrm{CH}_{2} \mathrm{Cl}_{2}$ provided the best yield for 4 , the slightly lower yield was obtained for 6 ( $85 \%$ yield), whereas the polar solvents such as $\mathrm{CH}_{3} \mathrm{CN}$ and $N, N^{\prime}$-dimethylformamide provided a better 
yield of $95 \%$ for 6 . Though the reaction can be performed without the inert atmosphere the presence of air leads to a $\sim 20 \%$ decrease in the TCBD yield.

It was known that alkyne attached with TCBD tends to undergo a second CA-RE reaction at high temperature to provide the octacyano[4]dendralenes as a new class of cyanorich non-planar organic acceptor. ${ }^{31}$ Compound $\mathbf{6}$ was subjected to further reaction with TCNEO to test whether the $\mathbf{6}$ having similar features would undergo additional [3+2] CA-RO reaction and provide the corresponding octacyano[4]dendralene i.e., 3,4-Bis(dicyanomethylidene)-2,5bis[4-(dimethylamino)phenyl]hexa-1,5-diene-1,1,6,6-tetracarbonitrile. However, both TLC and LC-MS have confirmed that such octacyano[4]dendralene did not form (Figures S4 and S5, SI). Nevertheless, a new blue-colored compound formed as major and its structural identity with different chemistry needs to be established with a greater detailed investigation which will be reported elsewhere.

The identity of the compounds was checked against the authentic sample of respective product formation in the reaction mixture using silica TLC prepared using TCNE, since all the TCBD products were already known through the [2+2] CA-RE reaction. Further, the successful formation of TCBDs 4 and $\mathbf{6}$ was characterized by melting point, ${ }^{1} \mathrm{H}-\mathrm{NMR}$, and unambiguous proof for the TCBD constitution obtained from the single-crystal study. While compound 4 provided the same structure as previously reported CCDC deposition number $256339,{ }^{11 a}$ in the case of TCBD 6, the obtained crystal structure (CCDC deposition number 2009612) is a new polymorphism (II) with monoclinic unit cell and $P 21 / \mathrm{c}$ (14) space group (Figure 2, for details, see Section E, SI), unlike the previously reported polymorphism (I) showing triclinic lattice with $\mathrm{P} \overline{1}$ space group (CCDC deposition number 56338). ${ }^{11 \mathrm{a}}$ The comparison table of these two polymorphs is provided in Table S1, SI.
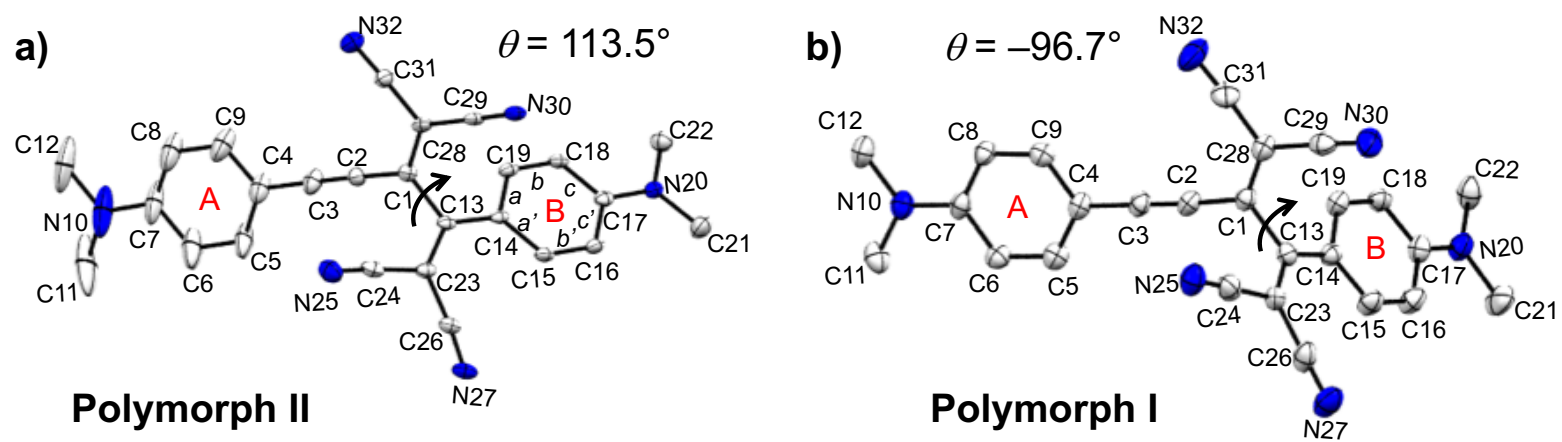

Figure 2. ORTEP plots of a) 6 polymorph II, b) 6 polymorph I $^{11 a}$ (arbitrary numbering, Hatoms are omitted for clarity). Atomic displacement parameters are drawn at a $25 \%$ probability level. 
The protocol established in the previous study shows that TCNEO acts as 1,3-dipolar species at above $100{ }^{\circ} \mathrm{C}$ and the generated carbonyl ylide undergoes [3+2] CA reaction with EDG-free alkyne to give stable TCDHF product under relatively harsher condition (Figure 3a). ${ }^{26,27}$ The mechanistic proposal for the present reaction is outlined in Figure $3 \mathrm{~b}$. The fact that the TCBDs formation by EDG-alkynes 3 and $\mathbf{5}$ proceeds at ambient and even at low $\left(0{ }^{\circ} \mathrm{C}\right)$ temperatures, respectively, indicates that the first step initiated by the nucleophilic attack by the EDG-activated alkyne assisted by the electron delocalization. This generates to form a zwitterionic intermediate $\mathbf{I}$, in which the cationic charge is favorably stabilized as an iminium ion and such step occurrence has postulated to form in the first step of the CA-RE reaction. ${ }^{32}$ Upon cyclization by the dicyanomethide anion generate the [3+2] cycloadduct intermediate i.e TCDHF derivative II (Figure 3b). Unlike the isolable furan adduct formed in the non-activated alkyne, ${ }^{26}$ the facile furan ring-opening and generation of oxide ion III are facilitated by the presence of electron delocalization from the EDG as well as the stabilization by the generation of donor-substituted dicyanovinyl (D-A) moiety. The removal of an oxygen atom (deoxygenation) from this derivative is a prerequisite for the formation of TCBD. This is achieved by without any extra reagent but with additional TCNEO molecule, which undergoes nucleophilic attack by the oxide anion at the electrophilic carbon atom generating the new oxide anion intermediate IV. The generation of push-pull TCBD may be formed via two pathways a and $\mathbf{b}$. In pathway a, the oxide anion intermediate IV undergoes a nucleophilic attack on the electrophilic oxygen atom to form the dioxetane ring and the stable push-pull TCBD molecule. The electrophilic character of the oxygen atom bonded between two $-\mathrm{C}(\mathrm{CN})_{2}$ has been proven before for the reaction between the TCNEO and anthracene. ${ }^{27 b}$ The generated unstable dioxetane further may decompose into two molecules of carbonyl cyanide $\left(\mathrm{CO}(\mathrm{CN})_{2}\right)$ via retro-electrocyclization. On the other hand, in pathway $\mathbf{b}$ the elimination of two $\mathrm{CO}(\mathrm{CN})_{2}$ and push-pull TCBD molecules may occur in a single step. To gain insights on which pathway is being governed in this reaction, we tested the in-situ reaction mixture and analyzed using LC-MS and ATR FT-IR studies to see whether the characteristic peaks corresponding to the dioxetane and $\mathrm{CO}(\mathrm{CN})_{2}$ are present. The ATR FT-IR spectrum of the crude reaction mixture has shown the characteristic peak corresponding to the dioxetane ring $\mathrm{O}-\mathrm{O}$ stretching frequency at $670 \mathrm{~cm}^{-1}$ which is absent in both TCBD and TCNEO (Figure S11, SI). ${ }^{33}$ Similarly, the LC-MS spectrum of the crude reaction mixture showed the presence of molecular ion ( $\mathrm{m} / \mathrm{z}$ 160.06 Daltons) peak corresponding to the 3,3,4,4-tetracyano-1,2-dioxetane (Figure S12, SI). Since both paths would eventually lead to the formation of $\mathrm{CO}(\mathrm{CN})_{2}$, the 
evidence for the presence of 3,3,4,4-tetracyano-1,2-dioxetane, in particular, suggests that path $\mathbf{a}$ is operated in the reaction.

a)

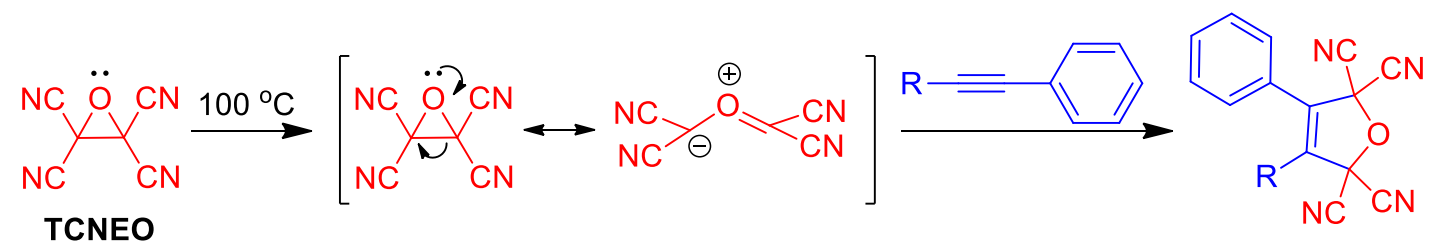

b)
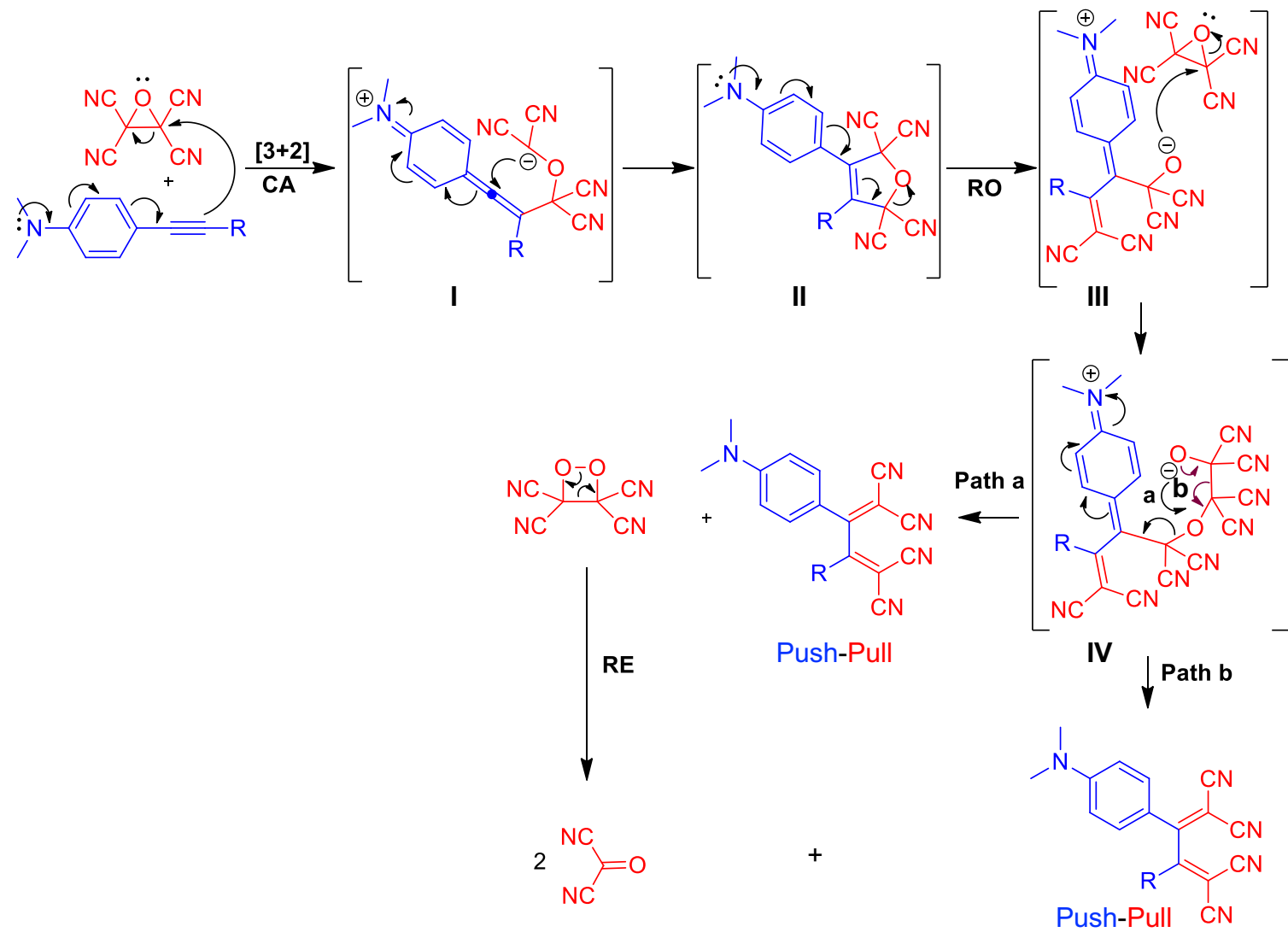

Figure 3. a) Temperature assisted-carbonyl ylide formation in EDG-free alkyne. ${ }^{27}$ b) Proposed mechanism for [3+2] CA-RO reaction for EDG-alkyne.

In conclusion, we demonstrated for the first time that EDG-substituted TCBDs can be synthesized from an unconventional method using TCNEO as the precursor instead of TCNE via [3+2] CA-RO reaction. Though mono-substituted alkynes gave very poor yield due to overreaction, di-substituted EDG-alkynes underwent smooth conversion under simpler conditions. Overall, the procedure is much simpler, greener, additive-free, and gives access to useful TCBDs in just a single step with excellent yields for di-substituted alkynes. The presence of EDG in the alkyne is the key to the successful synthesis of TCBDs which facilitated the RO reaction following the first step [3+2] CA reaction. A mechanism is proposed for the deoxygenation from the tetracyanodihydrofuran derivative is driven by the nucleophilic 
addition of another molecule of TCNEO leading to the formation of 3,3,4,4-tetracyano-1,2dioxetane that may decompose to carbonyl cyanide. FT-IR and LC-MS studies do indicate the formation of this key product. Though some shortcomings exist with the present methodology to synthesis TCBDs, such as mono-substituted alkynes does not yield clean product and not being atom-economical, but offers advantages like an alternative way to make TCBDs, disubstituted alkyne give chromophores with excellent yield, generally works with a very milder condition which means can be useful for those reactions requires harsher conditions under [2+2] CA-RE reaction, and lastly opens up a new window to explore different reactivity products to expand the chemical space for push-pull chromophores.

\section{Experimental section}

General procedure. A solution of TCNEO $(0.14 \mathrm{mmol})$ in an appropriate anhydrous degassed solvent $(10 \mathrm{~mL})$ was either cooled to $0{ }^{\circ} \mathrm{C}$ or at $25{ }^{\circ} \mathrm{C}$, treated dropwise EDG-alkyne 3 or $\mathbf{5}$ $(0.07 \mathrm{mmol})$, in a degassed appropriate solvent $(10 \mathrm{~mL})$ stirred at the same temperature for completion of reaction time upon monitoring the reaction by TLC $\left(\mathrm{SiO}_{2}\right)$. The solution color changes occur approximately after $3 \mathrm{~h}$. After evaporation of the solvent, $\mathrm{CH}_{2} \mathrm{Cl}_{2}$ and water were mixed and extracted with $\mathrm{CH}_{2} \mathrm{Cl}_{2}(3 \times 10 \mathrm{~mL})$. The combined organic layers were washed with brine, dried over anhydrous $\mathrm{Na}_{2} \mathrm{SO}_{4}$, and evaporated. The crude product was columned using silica (hexane/ $\mathrm{CH}_{2} \mathrm{Cl}_{2}$ 7:3) and recrystallized by slow diffusion of hexane into $\mathrm{CH}_{2} \mathrm{Cl}_{2}$ solution to afford the pure product.

\section{Conflicts of interest}

The authors declare no competing financial interest.

\section{Acknowledgments}

This work was supported by SERB, Department of Science and Technology (DST), grant nos. ECR/2016/000441 and SB/S2/RJN-047/2015. G.J. thanks DST-SERB for Ramanujan Fellowship. The authors thank Kamlesh Satpute and Dr. Nagaraja C. Mallaiah for access to the $\mathrm{X}$-ray facility at IIT-Ropar for the single crystal data collection and refinement and Panjab University (SAIF facility) for NMR data.

\section{Supporting Information}

Supporting Information is available. 


\section{Notes}

The authors declare no competing financial interest

\section{References}

1 (a) O. Ostroverkhova, Organic Optoelectronic Materials: Mechanisms and Applications, Chem. Rev. 2016, 116, 13279-13412; (b) M. Mayor, Molecular electronics--from a visionary concept towards reality, Chimia 2010, 64, 348-420.

2 (a) T. Vallaitis, S. Bogatscher, L. Alloatti, P. Dumon, R. Baets, M. L. Scimeca, I. Biaggio, F. Diederich, C. Koos, W. Freude and J. Leuthold, Optical properties of highly nonlinear silicon-organic hybrid (SOH) waveguide geometries, Opt. Express 2009, 17, 17357 17368; (b) L. Dou, Y. Liu, Z. Hong, G. Li and Y. Yang, Low-Bandgap Near-IR Conjugated Polymers/Molecules for Organic Electronics, Chem. Rev. 2015, 115, 12633-12665; (c) S. P. Senanayak, V. K. Sangwan, J. J. McMorrow, K. Everaerts, Z. Chen, A. Facchetti, M. C. Hersam, T. J. Marks and K. S. Narayan, Self-Assembled Photochromic Molecular Dipoles for High-Performance Polymer Thin-Film Transistors, ACS Appl. Mater. Interfaces. 2018, $10,21492-21498$.

3 (a) A.-I. Gopalan, S. S. Komathi, N. Muthuchamy, K.-P. Lee, M. J. Whitcombe, L. Dhana and G. Sai-Anand, Functionalized conjugated polymers for sensing and molecular imprinting applications, Prog. Polym. Sci. 2019, 88, 1-129; (b) L. Chen, D. Wu, J. Yoon, Recent Advances in the Development of Chromophore-Based Chemosensors for Nerve Agents and Phosgene. ACS Sens. 2018, 3, 27-43; (c) N. Dey, J. Kulhánek, F. Bureš and S. Bhattacharya, Simultaneous Detection of $\mathrm{Cu}^{2+}$ and $\mathrm{Hg}^{2+}$ via Two Mutually Independent Sensing Pathways of Biimidazole Push-Pull Dye, J. Org. Chem. 2019, 84, 1787-1796; (d) S. Pramanik, H. Deol, V. Bhalla and M. Kumar, AIEE Active Donor-Acceptor-DonorBased Hexaphenylbenzene Probe for Recognition of Aliphatic and Aromatic Amines, ACS Appl. Mater. Interfaces. 2018, 10, 12112-12123; (e) Y. Li, M. Ashizawa, S. Uchida and T. Michinobu, A Novel Polymeric Chemosensor: Dual Colorimetric Detection of Metal Ions Through Click Synthesis, Macromol. Rapid Commun. 2011, 32, 1804-1808.

4 P. Campagnola, Second Harmonic Generation Imaging Microscopy: Applications to Diseases Diagnostics, Anal. Chem. 2011, 83, 3224-3231.

5 (a) J. N. Clifford, E. Martınez-Ferrero, A. Viterisi and E. Palomares, Sensitizer molecular structure-device efficiency relationship in dye sensitized solar cells, Chem. Soc. Rev. 2011, 
40, 1635-1646; (b) M. Liang and J. Chen, Arylamine organic dyes for dye-sensitized solar cells, Chem. Soc. Rev. 2013, 42, 3453-3488.

6 F. Chen, J. Zhang, X. Wan, Design and Synthesis of Piezochromic Materials Based on PushPull Chromophores: A Mechanistic Perspective, Chem.-Eur. J. 2012, 18, 4558-4567.

7 A. Abbotto, L. Beverina, R. Bozio, S. Bradamante, C. Ferrante, G. A. Pagani and R. Signorini, Push-Pull Organic Chromophores for Frequency-Upconverted Lasing, $A d v$. Mater. 2000, 12, 1963-1967.

8 F. Wurthner, R. Wortmann and K. Meerholz, Chromophore Design for Photorefractive Organic Materials, Chem. Phys. Chem. 2002, 3, 17-31.

9 (a) M. Klikar, I. V. Kityk, D. Kulwas, T. Mikysek, O. Pytelaa and F. Bures, Multipodal arrangement of push-pull chromophores: a fundamental parameter affecting their electronic and optical properties, New J. Chem. 2017, 41, 1459-1472; (b) C. Koos, P. Vorreau, T. Vallaitis, P. Dumon, W. Bogaerts, R. Baets, B. Esembeson, I. Biaggio, T. Michinobu, F. Diederich, W. Freude and J. Leuthold, All-optical high-speed signal processing with silicon-organic hybrid slot waveguides, Nat. Photonics, 2009, 3, 216-219; (c) A. T. Bui, C. Philippe, M. Beau, N. Richy, M. Cordier, T. Roisnel, L. Lemiègre, O. Mongin, F. Paul and Y. Trolez, Synthesis, characterization and unusual near-infrared luminescence of 1,1,4,4tetracyanobutadiene derivatives, Chem. Commun. 2020, 56, 3571-3574.

$10 \mathrm{~F}$. Bures, Fundamental aspects of property tuning in push-pull molecules, $R S C A d v$. 2014, 4, 58826-58851.

11 (a) T. Michinobu, J. C. May, J. H. Lim, C. Boudon, J. P. Gisselbrecht, P. Seiler, M. Gross, I. Biaggio and F. Diederich, A new class of organic donor-acceptor molecules with large third-order optical nonlinearities, Chem. Commun. 2005, 737-739; (b) T. Michinobu, C. Boudon, J. P. Gisselbrecht, P. Seiler, B. Frank, N. N. P. Moonen, M. Gross and F. Diederich, Donor-Substituted 1,1,4,4-Tetracyanobutadienes (TCBDs): New Chromophores with Efficient Intramolecular Charge-Transfer Interactions by Atom-Economic Synthesis, Chem.-Eur. J. 2006, 12, 1889-1905; (c) T. Michinobu and F. Diederich, The [2+2] Cycloaddition-Retroelectrocyclization (CA-RE) Click Reaction: Facile Access to Molecular and Polymeric Push-Pull Chromophores, Angew. Chem. Int. Ed. 2018, 57, 35523577 .

12 S. Kato and F. Diederich, Non-planar push-pull chromophores, Chem. Commun. 2010, 46, 1994-2006. 
13 Y. Wang, S. W. Kim, J. Lee, H. Matsumoto, B. J. Kim and T. Michinobu, Dual ImideFunctionalized Unit-Based Regioregular D-A1-D-A2 Polymers for Efficient Unipolar n-Channel Organic Transistors and All-Polymer Solar Cells, ACS Appl. Mater. Interfaces. 2019, 11, 22583-22594.

14 M. T. Sharbati, F. Panahi and A. Gharavi, Near-Infrared Organic Light-Emitting Diodes Based on Donor-pi-Acceptor Oligomers, IEEE Photon. Technol. Lett. 2010, 22, 1695-1697.

15 W. Li, M. Otsuka, T. Kato, Y. Wang, T. Moril and T. Michinobu, 3,6-Carbazole vs 2,7carbazole: A comparative study of hole-transporting polymeric materials for inorganicorganic hybrid perovskite solar cells, Beilstein J. Org. Chem. 2016, 12, 1401-1409.

16 For a review, see: M. I. Bruce, Some Organometallic Chemistry of Tetracyanoethene: CNdisplacement and Cycloaddition Reactions with Alkynyl Transition Metal Complexes and Related Chemistry, Aust. J. Chem. 2011, 64, 77-103.

17 T. M. Pappenfus, D. K. Schneiderman, J. Casado, J. T. L. Navarrete, M. C. R. Delgado, G. Zotti, B. Vercelli, M. D. Lovander, L. M. Hinkle, J. N. Bohnsack and K. R. Mann, Oligothiophene Tetracyanobutadienes: Alternative Donor-Acceptor Architectures for Molecular and Polymeric Materials, Chem. Mater. 2011, 23, 823-831.

18 S.-i. Kato, M. Kivala, W. B. Schweizer, C. Boudon, J.-P. Gisselbrecht and F. Diederich, Origin of Intense Intramolecular Charge-Transfer Interactions in Nonplanar Push-Pull Chromophores, Chem.-Eur. J. 2009, 15, 8687-8691.

19 (a) T. Shoji, S. Ito, K. Toyota, M. Yasunami and N. Morita, Synthesis, Properties, and Redox Behavior of Mono-, Bis-, and Tris[1,1,4,4,- tetracyano-2-(1-azulenyl)-3-butadienyl] Chromophores Binding with Benzene and Thiophene Cores, Chem.-Eur. J. 2008, 14, 83988408; (b) T. Shoji, J. Higashi, S. Ito, T. Okujima, M. Yasunami and N. Morita, Synthesis of Redox-Active, Intramolecular Charge-Transfer Chromophores by the [2+2] Cycloaddition of Ethynylated 2H-Cyclohepta[b]furan-2-ones with Tetracyanoethylene, Chem.-Eur. J. 2011, 17, 5116-5129; (c) T. Shoji and S. Ito, Azulene-Based Donor-Acceptor Systems: Synthesis, Optical, and Electrochemical Properties, Chem.-Eur. J. 2017, 23, 16696-16709.

20 D. Koszelewski, A. Nowak-Król and D. T. Gryko, Selective Cycloaddition of Tetracyanoethene (TCNE) and 7,7,8,8-Tetracyanop-quinodimethane (TCNQ) to Afford meso-Substituted Phenylethynyl Porphyrins, Chem. Asian J. 2012, 7, 1887-1894.

21 S.-i Kato, H. Noguchi, S. Jin and Y. Nakamura, Synthesis and Electronic, Optical, and Electrochemical Properties of a Series of Tetracyanobutadiene-Substituted Carbazoles, Asian J. Org. Chem. 2016, 5, 246-256 
22 M. Betou, R. J. Durand, D. A. Sallustrau, C. Gousset, E. Le Coz, Y. R. Leroux, D. L. Toupet, E. Trzop, T. Roisnel and Y. Trolez, Reactivity of Functionalized Ynamides with Tetracyanoethylene: Scope, Limitations and Optoelectronic Properties of the Adducts, Chem. Asian J. 2017, 12, 1338-1346.

23 A. H. Dar, V. Gowri, A. Gopal, A. Muthukrishnan, A. Bajaj, S. Sartaliya, A. Selim, Md. E. Ali and G. Jayamurugan, Designing of Push-Pull Chromophores with Tunable Electronic and Luminescent Properties Using Urea as the Electron Donor, J. Org. Chem. 2019, 84, 8941-8947.

24 (a) T. A. Reekie, E. J. Donckele, L. Ruhlmann, C. Boudon, N. Trapp and F. Diederich, Ester-Substituted Electron-Poor Alkenes for Cycloaddition-Retroelectrocyclization (CARE) and Related Reactions, Eur. J. Org. Chem. 2015, 7264-7275; (b) E. J. Donckele, T. A. Reekie, N. Trapp and F. Diederich, Penta-2,4-dien-1-ones by Formal [3+2] CycloadditionRearrangement of Electron-Deficient Diethyl 2-(Dicyanomethylene)malonate with Alkynes, Eur. J. Org. Chem. 2016, 716-724.

25 (a) W. J. Linn, O. W. Webster and R. E. Benson, Tetracyanoethylene Oxide. I. Preparation and Reaction with Nucleophiles, J. Am. Chem. Soc. 1965, 87, 3651-3656; (b) W. J. Linn, Tetracyanoethylene oxide, Org. Synth. 1973, Coll. Vol. V, 1007.

26 W. J. Linn and R. E. Benson, Tetracyanoethylene Oxide. 11. Addition to Olefins, Acetylenes, and Aromatics, J. Am. Chem. Soc. 1965, 87, 3657-3665.

27 (a) W. J. Linn, Tetracyanoethylene Oxide. III. Mechanism of the Addition to Olefins, J. Am. Chem. Soc. 1965, 87, 3665-3672; (b) P. Brown and R. C. Cookson, Dipolar addition versus oxygen transfer in the reaction of tetracyanoethylene oxide with unsaturated hydrocarbons, Tetrahedron 1968, 24, 2551-2566.

28 (a) L. V. Frolova, I. V. Magedov, A. Harper, S. K. Jha, M. Ovezmyradov, G. Chandler, J. Garcia, D. Bethke, E. A. Shaner, I. Vasiliev and N. G. Kalugin, Tetracyanoethylene oxidefunctionalized graphene and graphite characterized by Raman and Auger spectroscopy, Carbon. 2015, 81, 216-222; (b) X. Peng, Y. Li, G. Zhang, F. Zhang and X. Fan, Functionalization of Graphene with Nitrile Groups by Cycloaddition of Tetracyanoethylene Oxide, J. Nanomaterials. 2013, 841789.

29 E. J. Donckele, A. D. Finke, L. Ruhlmann, C. Boudon, N. Trapp and F. Diederich, The [2 + 2] Cycloaddition-Retroelectrocyclization and [4 + 2] Hetero-Diels-Alder Reactions of 2(Dicyanomethylene)indan-1,3-dione with Electron-Rich Alkynes: Influence of Lewis Acids on Reactivity, Org. Lett. 2015, 17, 3506-3509. 
30 (a) G. Jayamurugan, A. D. Finke, J.-P. Gisselbrecht, C. Boudon, W. B. Schweizer and F. Diederich, One-Pot access to push-pull oligoenes by sequential [2+2] cycloadditionretroelectrocyclization reactions, J. Org. Chem. 2014, 79, 426-431; (b) G. Jayamurugan, J.P. Gisselbrecht, C. Boudon, F. Schoenebeck, W. B. Schweizer, B. Bernet and F. Diederich, Expanding the chemical space for push-pull chromophores by non-concerted $[2+2]$ and [4+2] cycloadditions: access to a highly functionalised 6,6-dicyanopentafulvene with an intense, low-energy charge-transfer band, Chem. Commun. 2011, 47, 4520-4522.

31 B. Brieten, Y.-L. Wu, P. D. Jarowski, J.-P. Gisselbrecht, C. Boudon, M. Griesser, C. Onitsch, G. Gescheidt, W. B. Schweizer, N. Langer, C. Lennartz and F. Diederich. Donorsubstituted octacyano[4]dendralenes: a new class of cyano-rich non-planar organic acceptors, Chem. Sci. 2011, 2, 88-93.

32 Y. Wu, P. D. Jarowski, W. B. Schweizer and F. Diederich, Mechanistic Investigation of the Dipolar [2+2] Cycloaddition-Cycloreversion Reaction between 4- $(\mathrm{N}, \mathrm{N}-$ Dimethylamino)phenylacetylene and Arylated 1,1-Dicyanovinyl Derivatives To Form Intramolecular Charge-Transfer Chromophores, Chem.-Eur. J. 2010, 16, 202-211.

33 K. R. Kopecky and R. R. Gomez, $\mathrm{O}-\mathrm{O}$ stretching frequencies of cyclic peroxides. Stabilization of peroxides by alkoxy substituents, Can J. Chem. 1984, 62, 277-279. 
New access to the synthesis of 1,1,4,4-tetracyanobuta-1,3-diene-based push-pull chromophores using tetracyanoethylene oxide via $[3+2]$ cycloaddition-ring opening reactions

Table of Contents (TOC):

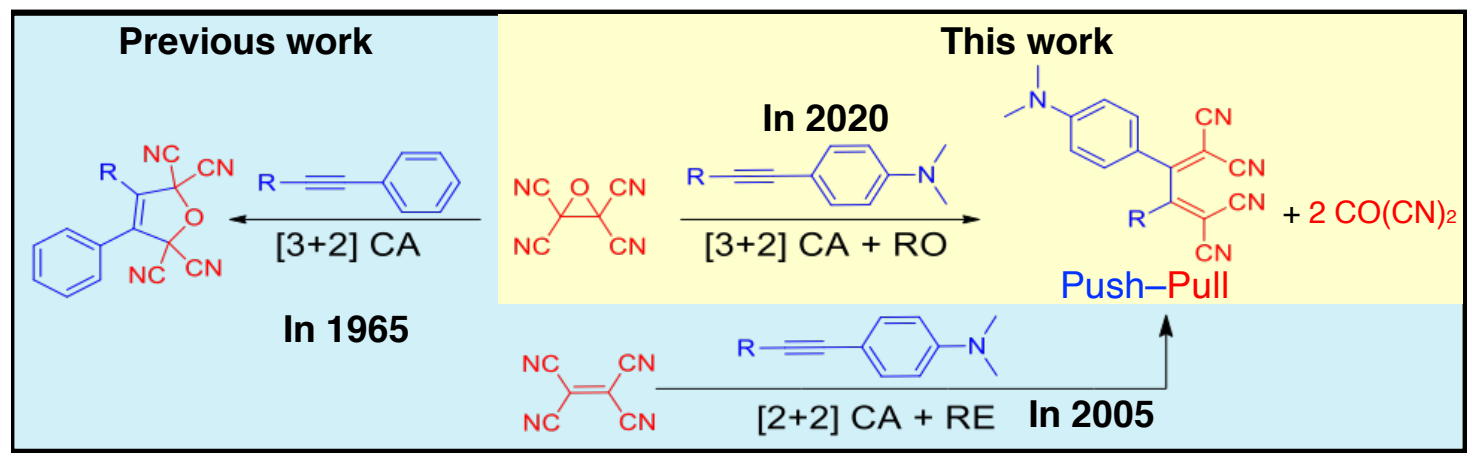

Unlike the [3+2] cycloadduct of the electron-donating group (EDG)-free alkynes with tetracyanoethylene oxide (TCNEO), the EDG induced [3+2] cycloadduct underwent facile ring-opening reaction to provide the very useful non-planar 1,1,4,4-tetracyanobuta-1,3-dienes (TCBDs) push-pull chromophores. This is the first report that provides access to TCBDs other than the $[2+2] \mathrm{CA}-\mathrm{RE}$ reaction with TCNE. 


\section{Supporting Information}

New access to the synthesis of 1,1,4,4-tetracyanobuta-1,3-diene-based push-pull chromophores using tetracyanoethylene oxide via $[3+2]$ cycloaddition-ring opening reactions

Arif Hassan Dar, ${ }^{\mathrm{a}}$ Vijayendran Gowri, ${ }^{\mathrm{a}}$ Neethu K. M, ${ }^{\mathrm{a}}$ Govindasamy Jayamurugan ${ }^{\mathrm{a}, *}$ anstitute of Nano Science and Technology, Mohali-160062, Punjab, India.

*Corresponding Author Email: jayamurugan@inst.ac.in.

$\begin{array}{lll}\text { Section } & \text { Table of Contents } & \text { Page }\end{array}$

A. General Methods and Materials $\quad$ S2

B. Monitoring of some reaction of alkynes with TCNEO

by TLC and LC S3

C. Synthetic Procedures and Characterization of the Products S6

$\begin{array}{lll}\text { D. } & { }^{1} \mathrm{H} \text { NMR spectra of TCBDs } 4 \text { and } 6 & \text { S7 }\end{array}$

E. X-ray Data for Compound $6 \quad S 8$

F. LC-MS and FT-IR studies of the crude reaction mixture S11

$\begin{array}{ll}\text { G. } & \text { References }\end{array}$ 


\section{Experimental Section}

\section{A. General Methods and Materials.}

All reagents and solvents were obtained from commercial suppliers (Aldrich and TCI-India) and used without further purification. $\mathrm{CH}_{3} \mathrm{CN}, \mathrm{CH}_{2} \mathrm{Cl}_{2}$ was freshly distilled from $\mathrm{CaH}_{2}$ under the nitrogen $\left(\mathrm{N}_{2}\right)$ atmosphere. Column chromatography $(\mathrm{CC})$ was carried out with neutral silica gel. Thin-layer chromatography (TLC) was performed on precoated plastic sheets of silica gel G/UV-254 of $0.2 \mathrm{~mm}$ thickness (MachereyNagel, Germany) using appropriate solvents and visualized with UV light $(\lambda=254 \mathrm{~nm})$. Melting points (M.p.) were measured in open capillaries with a Stuart (automatic melting point SMP50) apparatus and are uncorrected. "Decomp" refers to decomposition. ${ }^{1} \mathrm{H}$ NMR spectra were measured on Bruker Avance II $400 \mathrm{MHz}$ instrument at $25{ }^{\circ} \mathrm{C}$ in $\mathrm{CDCl}_{3}$ or DMSO- $d_{6}$. Residual solvent signals in the ${ }^{1} \mathrm{H}$ NMR spectra were used as an internal reference. Chemical shifts $(\delta)$ are reported in ppm downfield from $\mathrm{SiMe}_{4}$, with the residual solvent signal. Coupling constants $(J)$ are given in Hz. The apparent resonance multiplicity is described as s (singlet), $\mathrm{d}$ (doublet), $\mathrm{t}$ (triplet), and $\mathrm{m}$ (multiplet). Transmission Spectra were measured using ATR-FT-IR Bruker Vertex 70; signal designations; s (strong), m (medium), and w (weak). Single-crystal X-ray diffraction data were collected using a Rigaku XtaLABmini Xray diffractometer equipped with a Mercury charge-coupled device detector with graphite monochromatic Mo K $\alpha$ radiation $(\lambda=0.71073 \AA)$ at 100.0 (2) K using $\omega$ scans. The data were reduced using CrysAlisPro 1.171.38.46, and the space group determination was done using Olex2.37 The crystal structures were solved by using ShelXT38 and were refined using ShelXL39 through Olex2 suite. All of the hydrogen atoms were geometrically fixed and refined using the riding model. Absorption correction was done by a multiscan method. All of the packing and interaction diagrams have been generated using Mercury. Liquid chromatography (LC) was performed on a Waters ACQUITY UPLC M-Class LC instrument using a Zorbax Eclipse Plus C18 column $(250 \times 4.6 \mathrm{~mm} ; 5 \mu \mathrm{m}$ pore size $)$ from Agilent. 


\section{B Monitoring of reaction of alkynes with TCNEO by TLC and LC}
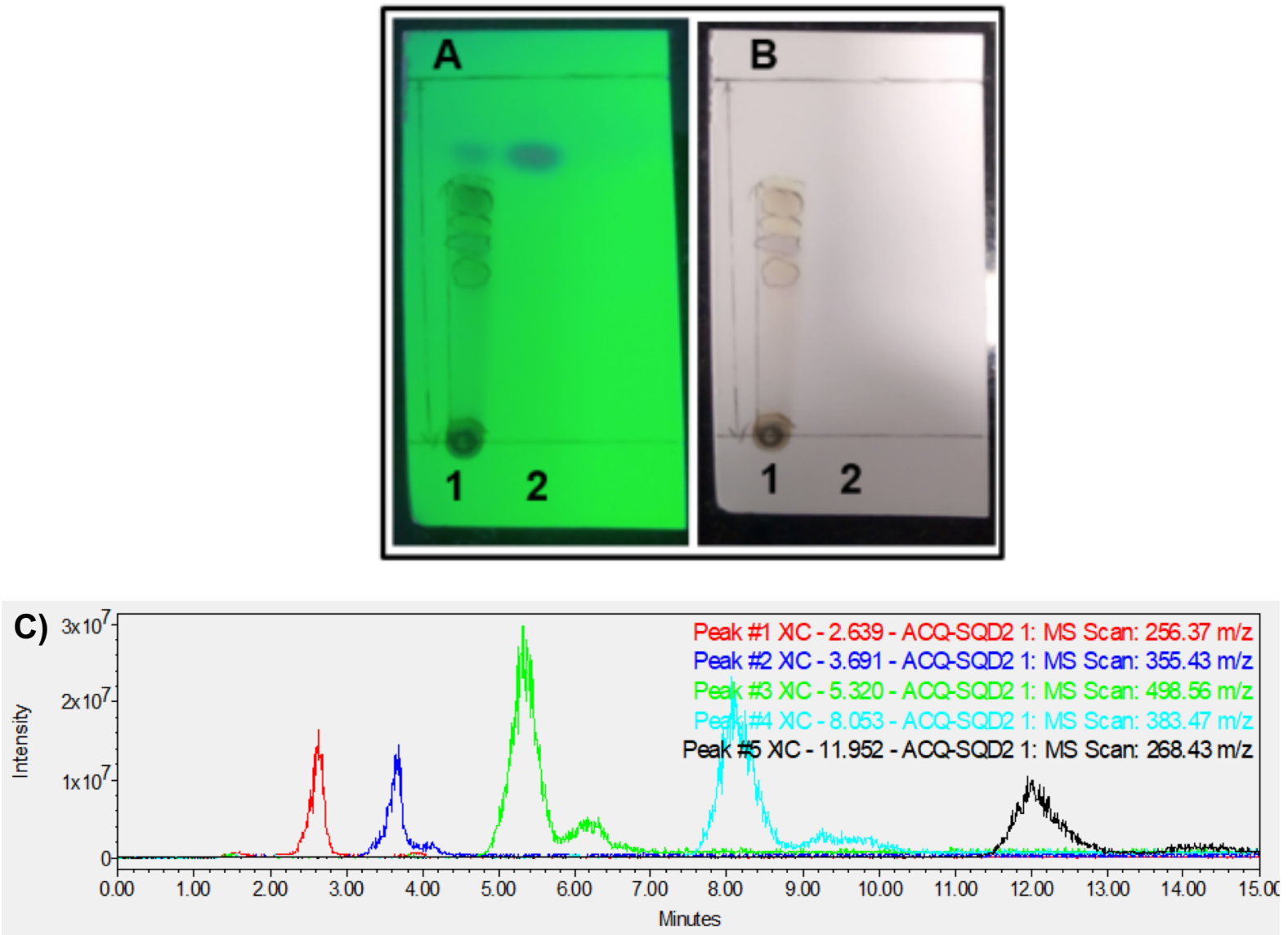

Figure S1. TLC of 4-ethynyl- $N, N^{\prime}$-dimethylaniline 1 with one equivalent (equiv) of TCNEO in $\mathrm{CH}_{2} \mathrm{Cl}_{2}$ (TLC eluent: EtOAc/hexane 25:75) visualized in the A) presence and $\mathrm{B}$ ) absence of UV light $(280 \mathrm{~nm})$. Spot 1 indicates the reaction mixture and spot 2 is starting material 1 . Note: some spots are visible with the naked eye than in the photo due to less intensity. C) LC-MS profile for entry 1 in Table 1 (main manuscript). 

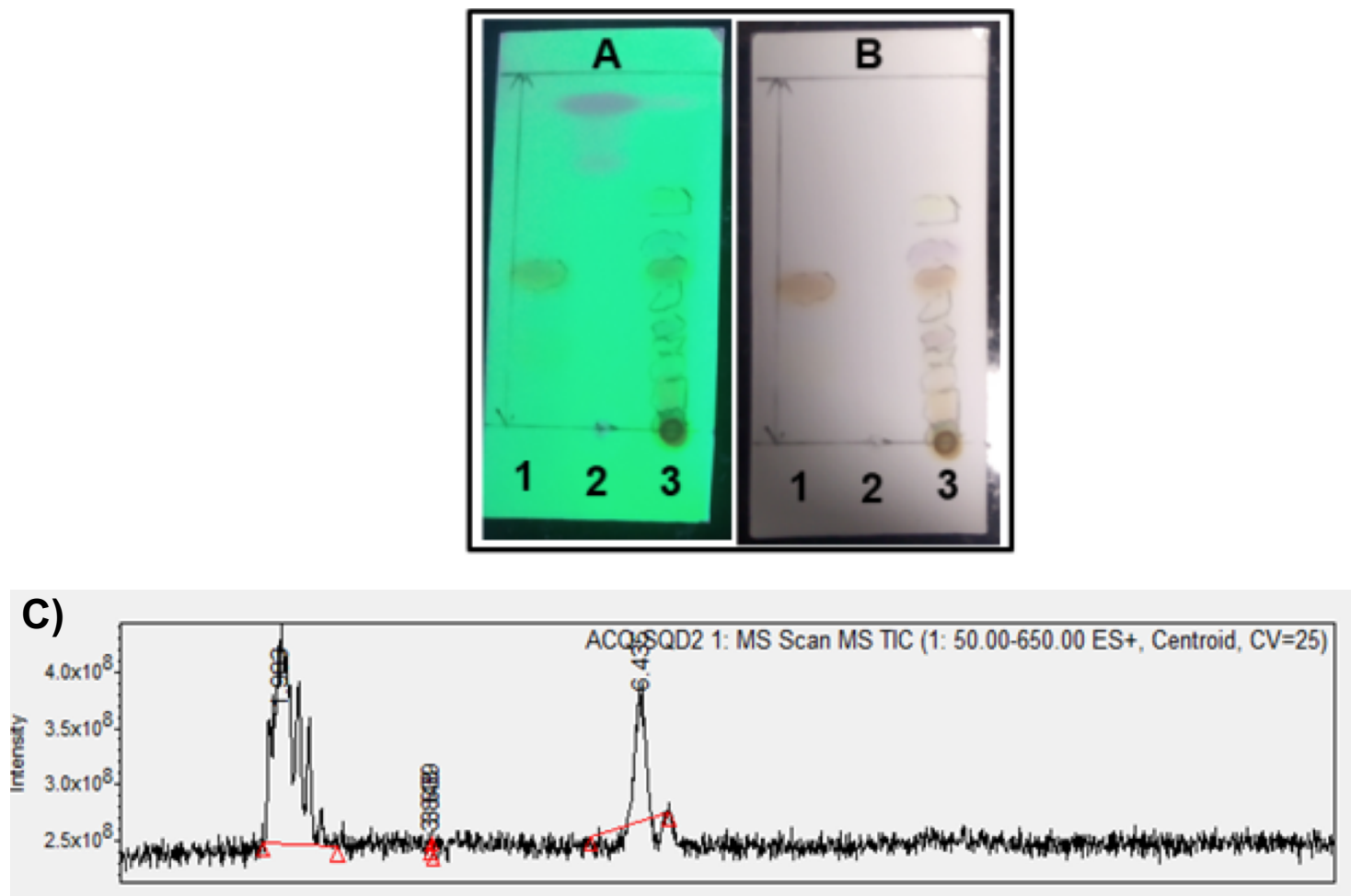

Figure S2. TLC of 4-ethynyl- $N, N^{\prime}$-dimethylaniline 1 with 1 equiv of TCNEO in $\mathrm{CH}_{3} \mathrm{CN}$ (TLC eluent: EtOAc/hexane 25:75) visualized in the A) presence and B) absence of UV light (280 $\mathrm{nm}$ ). Spot 1 indicates the authentic compound 2, spot 2 corresponds to the starting material $\mathbf{1}$, and spot 3 is the reaction mixture. C) LC-MS profile for entry 2 in Table 1 (main manuscript).

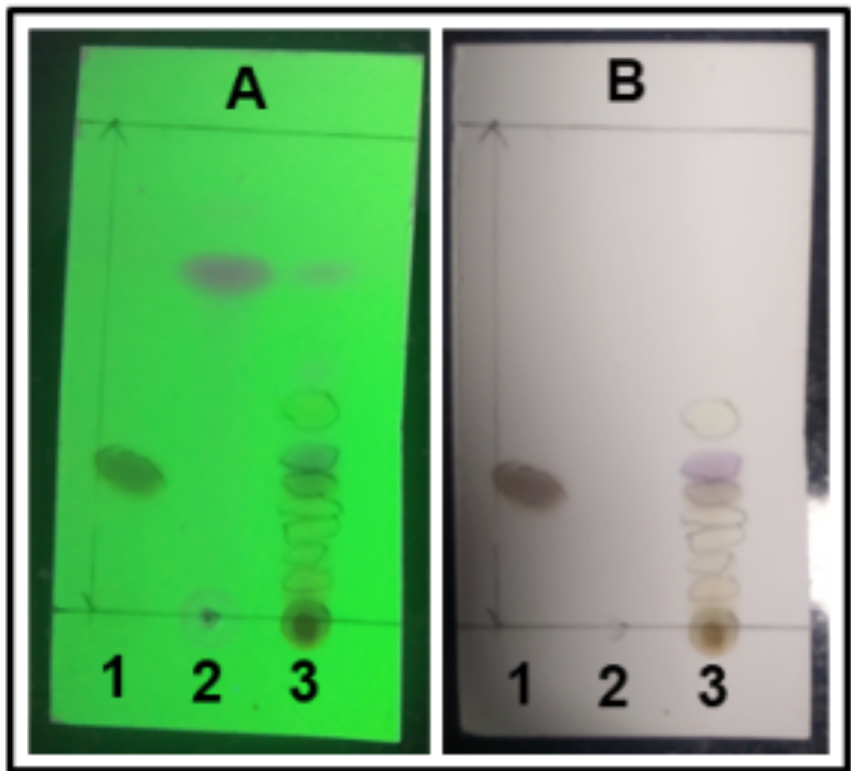

Figure S3. TLC of 4-ethynyl- $N, N^{\prime}$-dimethylaniline 1 with 2 equiv of TCNEO in $\mathrm{CH}_{2} \mathrm{Cl}_{2}$ at $25{ }^{\circ} \mathrm{C}$ (TLC eluent: EtOAc/hexane 20:80) visualized in the A) presence and B) absence of UV 
light $(280 \mathrm{~nm})$. Spot 1 indicates the authentic compound 2, spot 2 corresponds to the starting material $\mathbf{1}$, and spot 3 is the reaction mixture for entry 4 in Table 1 (main manuscript).

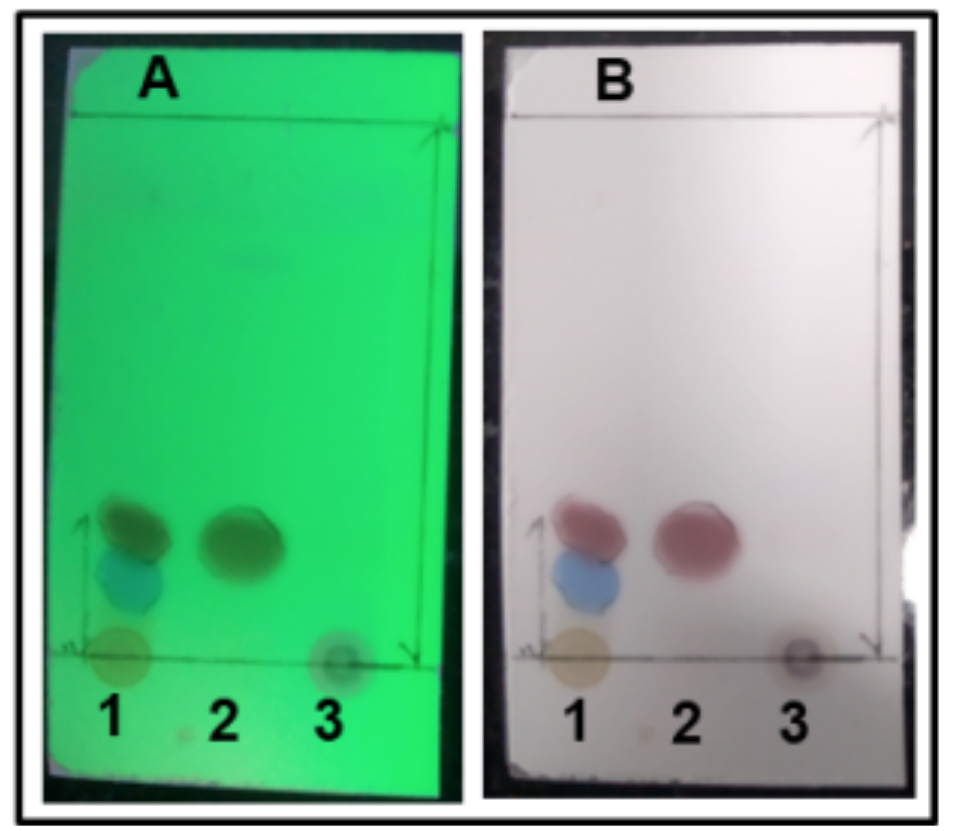

Figure S4. TLC of chromophore 6 with 1 equiv of TCNEO in $\mathrm{ClCH}_{2} \mathrm{CH}_{2} \mathrm{Cl}$ at $110{ }^{\circ} \mathrm{C}, 24 \mathrm{~h}$ (TLC eluent: EtOAc/hexane 15:85) visualized in the A) presence and B) absence of UV light $(280 \mathrm{~nm})$. Spot 1 is reaction mixture, spot 2 correspond to the starting material $\mathbf{6}$, spot 3 correspond to the authentic compound octacyano[4]dendralene i.e., 3,4Bis(dicyanomethylidene)-2,5-bis[4-(dimethylamino)phenyl]hexa-1,5-diene- $\quad 1,1,6,6$ tetracarbonitrile synthesized as per literature. ${ }^{2}$

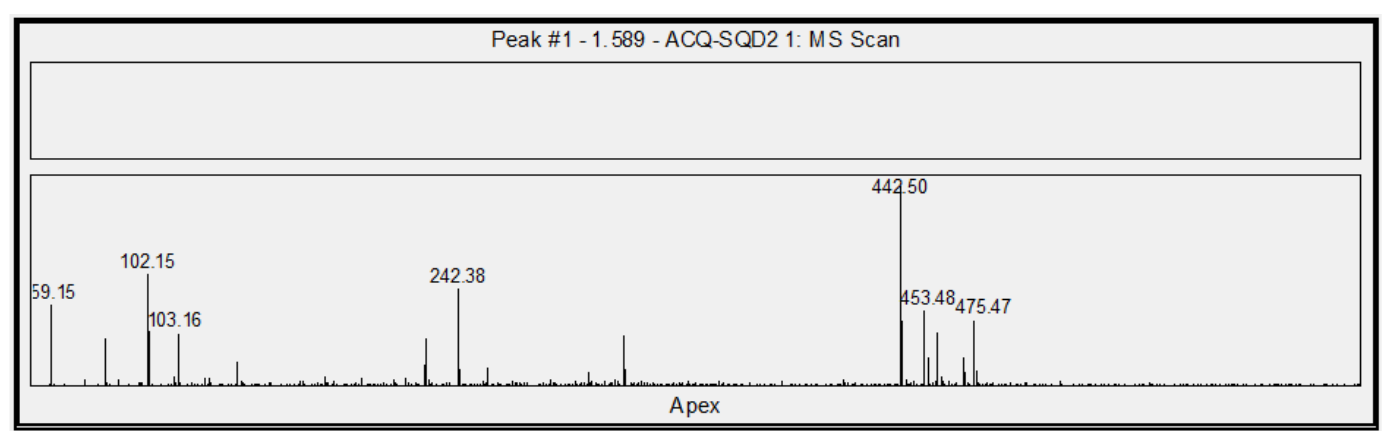

Figure S5. LC-MS profile of the above reaction (Figure S4) indicating the newly formed blue spot does not correspond to the octacyano[4]dendralene i.e., 3,4-Bis(dicyanomethylidene)-2,5bis[4-(dimethylamino)phenyl]hexa-1,5-diene- 1,1,6,6-tetracarbonitrile whose calculated mass is $\left\{\mathrm{C}_{32} \mathrm{~N}_{20} \mathrm{~N}_{10}\right\}: 544.18$. 


\section{Synthetic Procedures and Characterization of the Products}

\section{C1. Synthesis and characterization of push-pull chromophore $4^{1}$ using TCNEO}

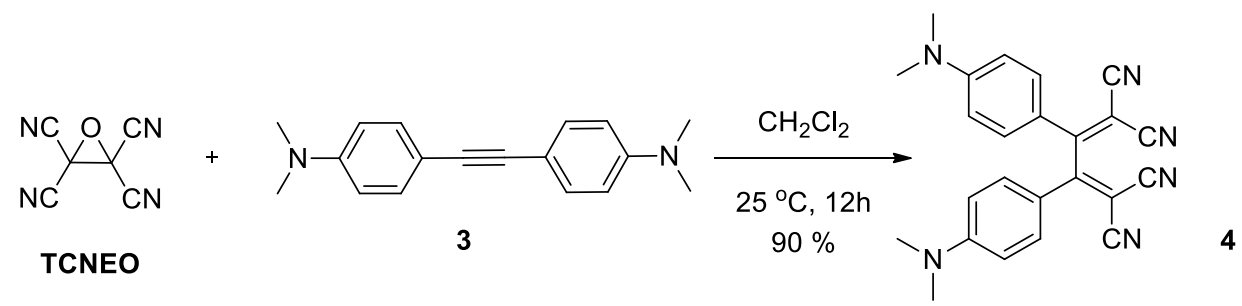

A solution of TCNEO (20 mg, $0.14 \mathrm{mmol})$ in anhydrous degassed $\mathrm{CH}_{2} \mathrm{Cl}_{2}(10 \mathrm{~mL})$ was treated dropwise 4,4'-(ethyne-1,2-diyl)bis( $N, N^{\prime}$-dimethylaniline) 3 (18 mg, $\left.0.07 \mathrm{mmol}\right)$ at $25{ }^{\circ} \mathrm{C}$, in degassed $\mathrm{CH}_{2} \mathrm{Cl}_{2}$ solvent $(10 \mathrm{~mL})$ stirred at the same temperature for $12 \mathrm{~h}$. The solution color changes occur approximately after $3 \mathrm{~h}$. To the reaction mixture saturated $\mathrm{NaCl}$ solution was poured and extracted with $\mathrm{CH}_{2} \mathrm{Cl}_{2}(3 \times 10 \mathrm{~mL})$. The combined organic layers were washed with brine, dried over anhydrous $\mathrm{Na}_{2} \mathrm{SO}_{4}$, and evaporated. The crude product was columned using silica (hexane/ $\mathrm{CH}_{2} \mathrm{Cl}_{2}$ 7:3) and recrystallized by slow diffusion of hexane into $\mathrm{CH}_{2} \mathrm{Cl}_{2}$ to afford the pure product $4^{1}$ (49 $\mathrm{mg}, 90 \%$ yield). $\mathrm{R}_{f}=0.3\left(\mathrm{SiO}_{2}\right.$; hexane $\left./ \mathrm{CH}_{2} \mathrm{Cl}_{2} 7: 3\right)$ Reddish metallic solid, M. P. $274-275{ }^{\circ} \mathrm{C}$ (decomp.); ${ }^{1 \mathrm{l}} \mathrm{H}-\mathrm{NMR}\left(400 \mathrm{MHz} ; 298 \mathrm{~K}, \mathrm{CDCl}_{3}\right) \delta=3.14$ (s, $\left.12 \mathrm{H}\right)$, $6.70(\mathrm{~d}, J=9.0 \mathrm{~Hz}, 4 \mathrm{H}), 7.79 \mathrm{ppm}(\mathrm{d}, J=9.0 \mathrm{~Hz}, 4 \mathrm{H})$.

\section{C2. Synthesis and characterization of push-pull Chromophore $\mathbf{6}^{1}$ using TCNEO}

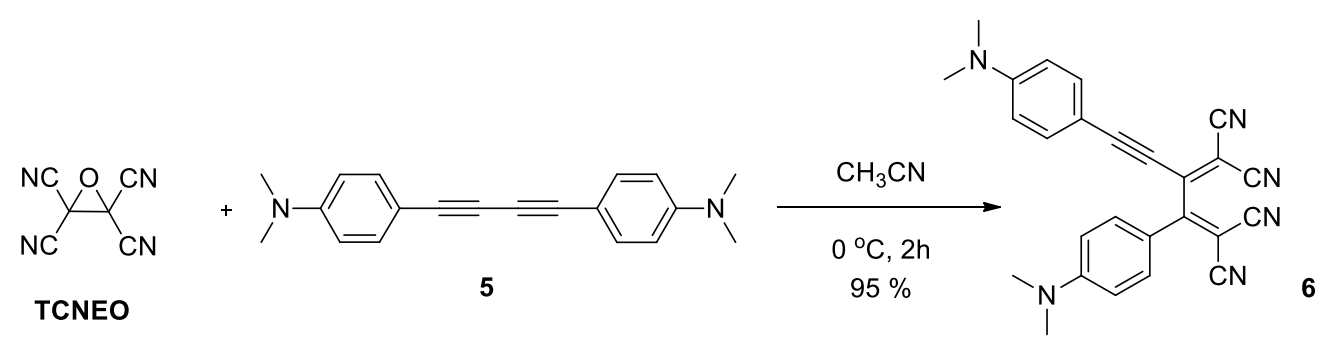

A solution of TCNEO (20 mg, $0.14 \mathrm{mmol})$ in anhydrous degassed $\mathrm{CH}_{3} \mathrm{CN}(10 \mathrm{~mL})$ was cooled at $0{ }^{\circ} \mathrm{C}$, treated dropwise 4,4'-(buta-1,3-diyne-1,4-diyl)bis( $N, N^{\prime}$-dimethylaniline) 5 (20 mg, $0.07 \mathrm{mmol})$, in degassed $\mathrm{CH}_{3} \mathrm{CN}(10 \mathrm{~mL})$ stirred at the same temperature for $2 \mathrm{~h}$. After completion of the reaction, acetonitrile was vacuum evaporated. The residue was dissolved in $\mathrm{CH}_{2} \mathrm{Cl}_{2}$ and mixed with water and extracted with $\mathrm{CH}_{2} \mathrm{Cl}_{2}(3 \times 10 \mathrm{~mL})$. The combined organic layers were washed with brine, dried over anhydrous $\mathrm{Na}_{2} \mathrm{SO}_{4}$, and evaporated. The crude product was columned using silica (hexane $/ \mathrm{CH}_{2} \mathrm{Cl}_{2}$ 7:3) and recrystallized by slow diffusion of hexane into $\mathrm{CH}_{2} \mathrm{Cl}_{2}$ to afford the pure product $\mathbf{6}^{1}\left(55 \mathrm{mg}, 95 \%\right.$ yield). $\mathrm{R}_{f}=0.3\left(\mathrm{SiO}_{2}\right.$; hexane $/ \mathrm{CH}_{2} \mathrm{Cl}_{2}$ 8:2) Black coloured solid, M. P. $190-193{ }^{\circ} \mathrm{C}$ (decomp.); ${ }^{\text {a }}{ }^{1} \mathrm{H}-\mathrm{NMR}$ (400 MHz, 
$\left.298 \mathrm{~K} ; \mathrm{CDCl}_{3}\right) \delta=3.14(\mathrm{~s}, 6 \mathrm{H}), 3.04(\mathrm{~s}, 6 \mathrm{H}), 6.62(\mathrm{~d}, J=8.0 \mathrm{~Hz}, 2 \mathrm{H}), 6.70(\mathrm{~d}, J=8.0 \mathrm{~Hz}, 2$ H), $7.47(\mathrm{~d}, J=8.0 \mathrm{~Hz}, 2 \mathrm{H}), 7.78 \mathrm{ppm}(\mathrm{d}, J=8.0 \mathrm{~Hz}, 2 \mathrm{H})$.

D. ${ }^{1} \mathrm{H}-\mathrm{NMR}$ spectra of TCBDs 4 and 6

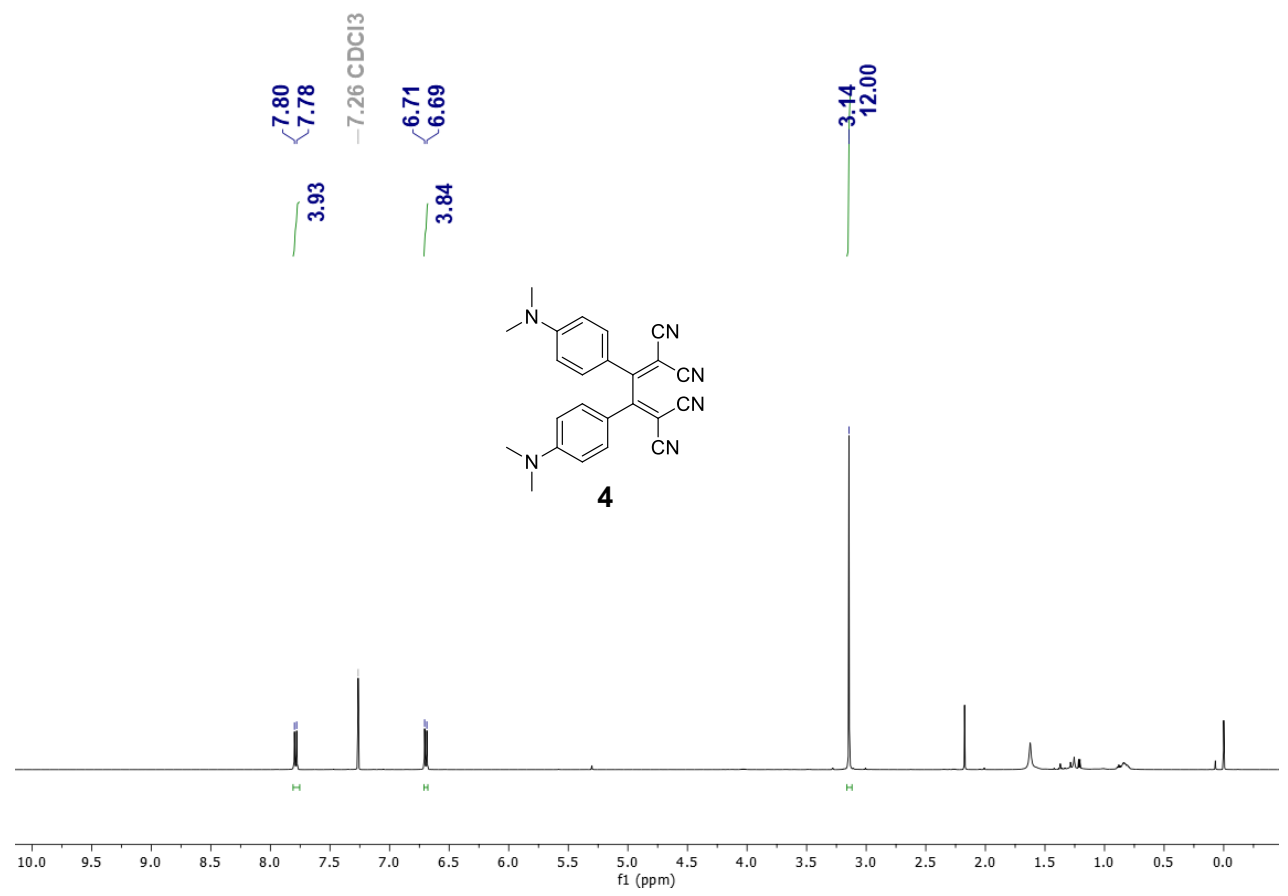

Figure S6. $400 \mathrm{MHz}{ }^{1} \mathrm{H}$ NMR spectrum of 4 recorded at $298 \mathrm{~K}$ in $\mathrm{CDCl}_{3}$.
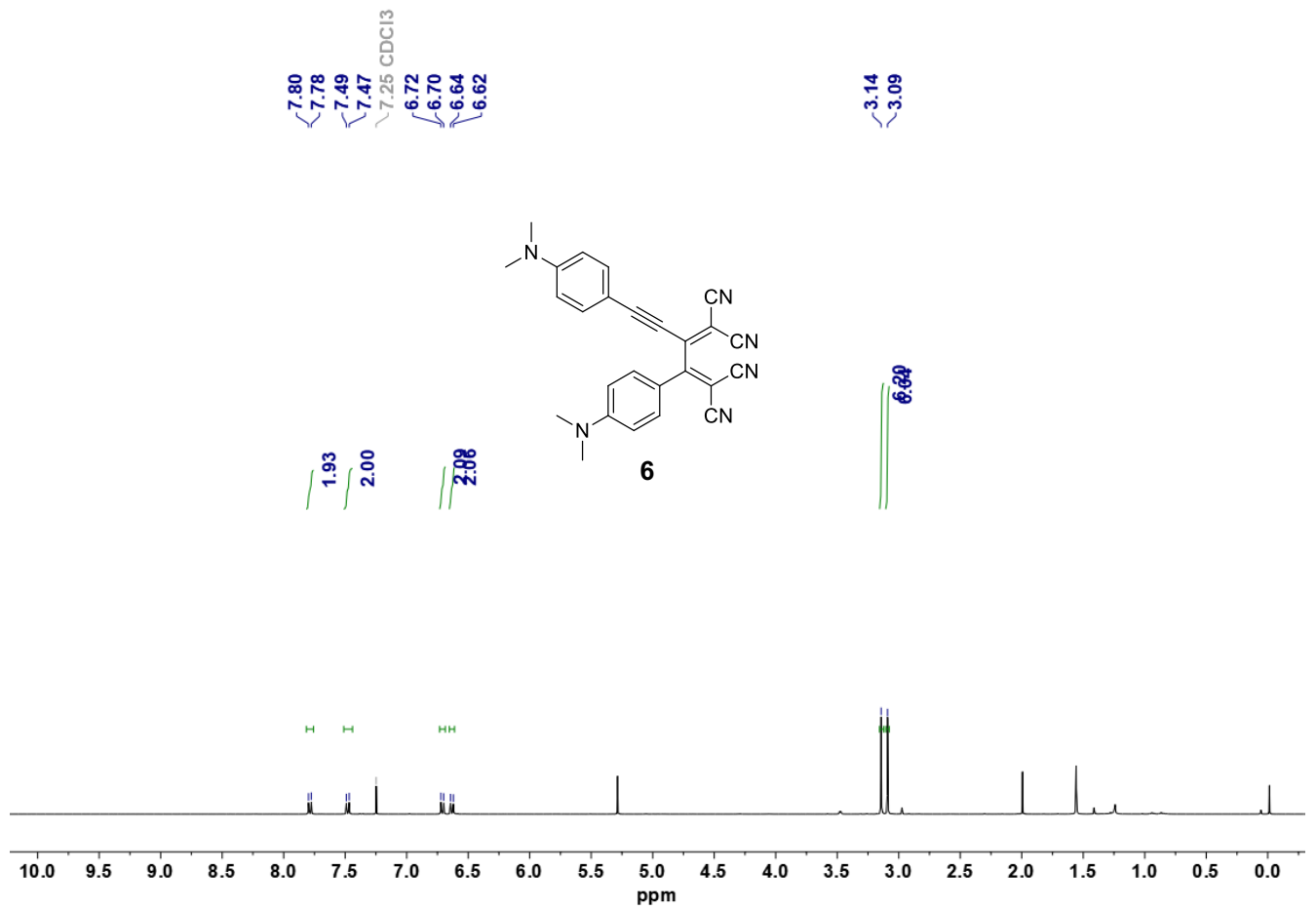

Figure S7. $400 \mathrm{MHz}{ }^{1} \mathrm{H}$ NMR spectrum of 6 recorded at $298 \mathrm{~K}$ in $\mathrm{CDCl}_{3}$. 


\section{E. X-ray Data for Compound 6}

The crystal structure obtained in the previous study using TCNE is called here as polymorph $\mathbf{I}^{1 \mathrm{a}}$ and in this study using TCNEO is called polymorph II.

Table S1. Crystal structure data and experimental details of polymorph-I ${ }^{1 \mathrm{a}}$ and $-\mathbf{I I}$ of 6.

\begin{tabular}{|c|c|c|}
\hline & Polymorph I & Polymorph II \\
\hline \multicolumn{3}{|l|}{ Crystal data } \\
\hline CCDC deposition number & 256338 & 2009612 \\
\hline Chemical formula & $\mathrm{C}_{26} \mathrm{H}_{20} \mathrm{~N}_{6} \cdot 2\left(\mathrm{CH}_{2} \mathrm{Cl}_{2}\right)$ & $\mathrm{C}_{26} \mathrm{H}_{20} \mathrm{~N}_{6}$ \\
\hline$M_{\mathrm{r}}\left(\mathrm{g} \mathrm{mol}^{-1}\right)$ & 586.33 & 416.48 \\
\hline Crystal system, space group & Triclinic, $P \overline{1}$ (no.2) & Monoclinic, $P 2_{1} / \mathrm{c}($ no. 14$)$ \\
\hline Temperature $(K)$ & 263 & 298 \\
\hline $\mathrm{a}, \mathrm{b}, \mathrm{c}(\AA)$ & $\begin{array}{l}\text { 7.3661(1), 9.5653(2), } \\
20.8690(4)\end{array}$ & $\begin{array}{l}\text { 17.2509(19), 17.0756(17), } \\
8.2275(9)\end{array}$ \\
\hline$\beta\left(^{\circ}\right)$ & $95.014(7)$ & $94.912(4)$ \\
\hline$V\left(\AA^{3}\right)$ & $1462.03(5)$ & $2414.7(4)$ \\
\hline$Z$ & 2 & 4 \\
\hline Radiation type & Mo $\mathrm{K}_{\alpha}$ & Mo $\mathrm{K}_{\alpha}$ \\
\hline$\mu\left(\mathrm{mm}^{-1}\right)$ & & 0.071 \\
\hline Crystal size (mm) & & $0.10 \times 0.31 \times 0.34$ \\
\hline \multicolumn{3}{|l|}{ Data collection } \\
\hline Diffractometer & Bruker-Nonius Kappa-CCD & $\begin{array}{l}\text { Bruker D8 Venture } \\
\text { PHOTON } 100\end{array}$ \\
\hline Absorption correction & & Multi-scan \\
\hline$T_{\min }, T_{\max }$ & & $0.592,0.745$ \\
\hline $\begin{array}{l}\text { Number of measured, } \\
\text { Independent and observed }[I \\
>2 \sigma(I)] \text { reflections }\end{array}$ & 11122,6573 , and 5258 & 24495,4907 and 3253 \\
\hline$R_{\text {int }}$ & 0.03 & 0.0568 \\
\hline $\mathrm{R}_{\text {sigma }}$ & & 0.0569 \\
\hline$(\sin \theta / \lambda)_{\max }\left(\AA^{-1}\right)$ & 0.7107 & 0.71073 \\
\hline \multicolumn{3}{|l|}{ Refinement } \\
\hline$R\left[\mathrm{~F}^{2}>2 \sigma\left(F^{2}\right)\right], \mathrm{w} R\left(F^{2}\right), \mathrm{S}$ & & $\begin{array}{l}0.0963(3253), 0.2434 \\
(4907), 1.03\end{array}$ \\
\hline Number of reflections & 2223 & 4907 \\
\hline Number of parameters & 348 & 289 \\
\hline
\end{tabular}



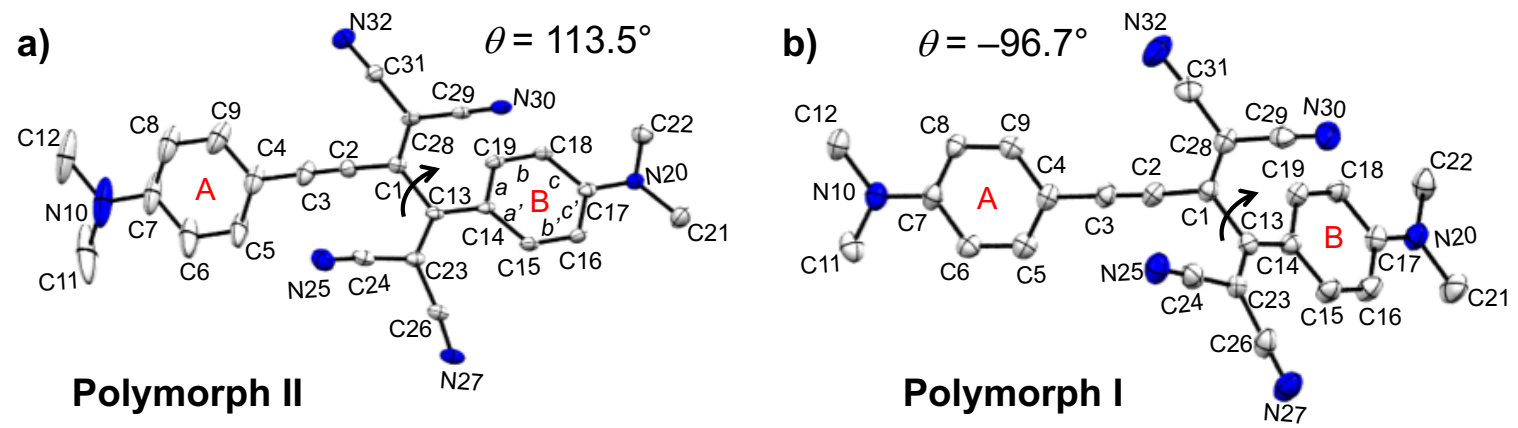

Figure S8. a) ORTEP plot of 6 polymorph II (arbitrary numbering, H-atoms are omitted for clarity). Atomic displacement parameters are drawn at a 25\% probability level. Selected bond lengths $[\AA]$, angles $\left[{ }^{\circ}\right]$, and torsional angles $\left[{ }^{\circ}\right]$ : $\mathrm{C} 1-\mathrm{C} 2$ 1.386(12), C1-C13 1.503(11), C2-C3 1.2092(11), C3-C4 1.434(12), C4-C5 1.383(12), C4-C9 1.3742(12), C5-C6 1.372(11), C6C7 1.424(11), C7-N10 1.362(10), C7-C8 1.386(11), C8-C9 1.3883(10), C13-C14 1.433(10), C14-C15 1.408(11), C14-C19 1.407(10), C15-C16 1.367(11), C16-C17 1.427(11), C17-N20 1.342(10), C17-C18 1.404(11), C18-C19 1.363(10), C28-C1-C13 120.30(7), C3-C2-C1 177.73(8), C2-C3-C4 178.20(8), C23-C13-C1 114.337(6), C24-C23-C26 111.528(7), C31C28-C29 116.61(8), C14-C13-C1-C28: -67.26 (8), C15-C14-C13-C23: -15.15(8), C28C1-C13-C23: 113.48(8), C31-C28-C1-C2: 2.47(8). b) ORTEP plot of $\mathbf{6} \cdot \mathbf{2} \mathbf{C H}_{\mathbf{2}} \mathbf{C l}_{\mathbf{2}}$ polymorph $\mathbf{I}^{1 \text { a }}$ (arbitrary numbering, H-atoms are omitted for clarity). Atomic displacement parameters are drawn at a $25 \%$ probability level. Selected bond lengths $[\AA]$, angles $\left[{ }^{\circ}\right]$, and torsional angles $\left[^{\circ}\right]$ : $\mathrm{C} 1-\mathrm{C} 2$ 1.396(12), C1-C13 1.514(11), C2-C3 1.178(11), C3-C4 1.431(12), C4-C5 1.392(12), C4-C9 1.416(12), C5-C6 1.358(11), C6-C7 1.409(11), C7-N10 1.371(10), C7-C8 1.422(11), C8-C9 1.349(10), C13-C14 1.431(10), C14-C15 1.394(11), C14-C19 1.407(10), C15-C16 1.347(11), C16-C17 1.401(11), C17-N20 1.335(10), C17-C18 1.395(11), C18-C19 1.364(10), C28-C1-C13 120.5(7), C3-C2-C1 175.2(8), C2-C3-C4 178.8(8), C23-C13-C1 113.3(6), C24-C23-C26 114.0(7), C31-C28-C29 116.6(8), C15C14-C13-C23:-4.35 (8), C28-C1-C13-C23:-96.64(8), C31-C28-C1-C2: 2.53(8). 

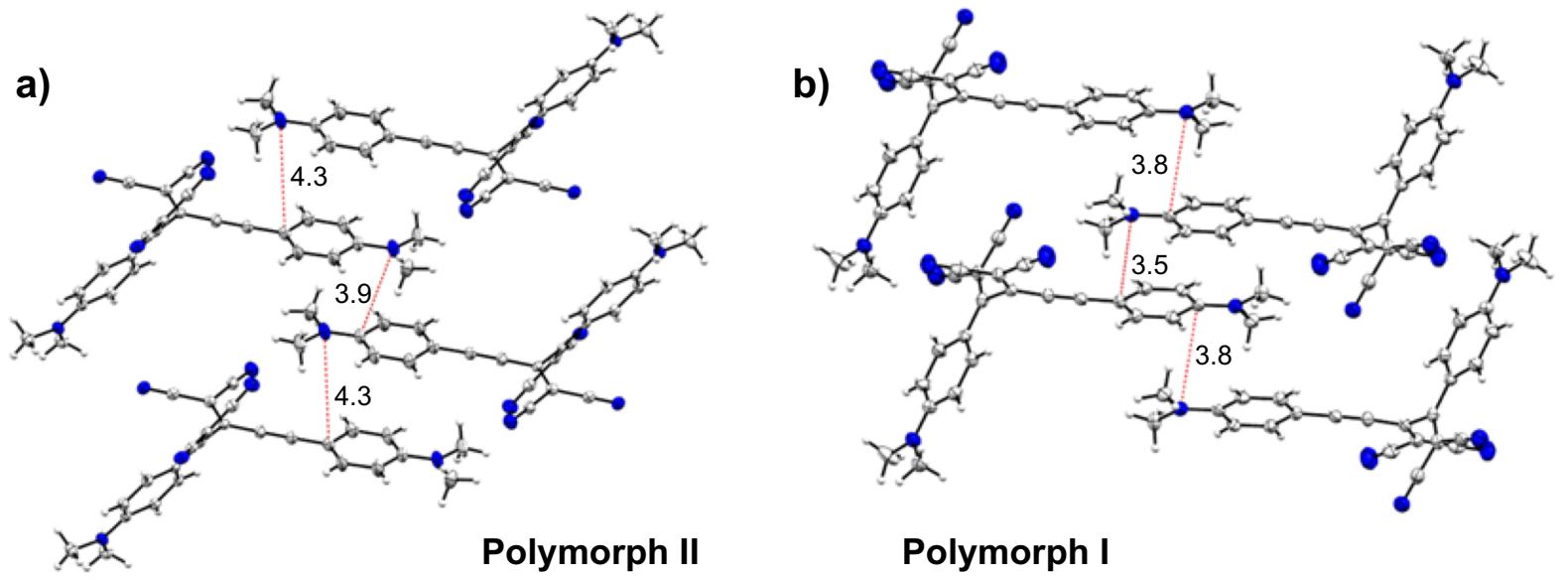

Polymorph I

Figure S9. Arrangement of neighboring molecules in the crystal packing of a) 6 in polymorph II, b) $6 \cdot 2 \mathrm{CH}_{2} \mathrm{Cl}_{2}{ }^{\text {a a }}$ in polymorph $\mathrm{I}$.

a)

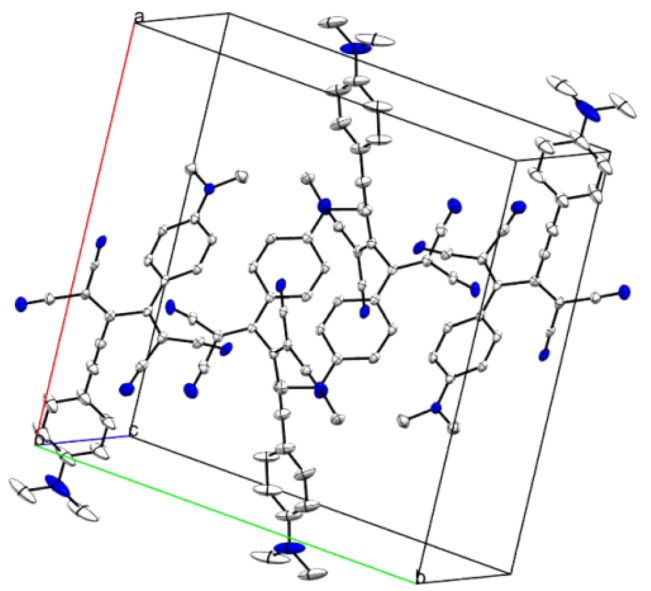

Polymorph II b)

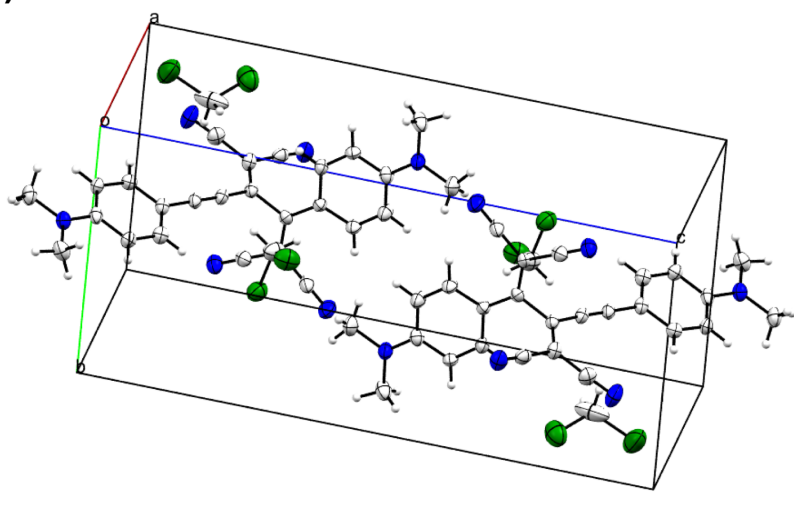

Polymorph I

Figure S10. Unit cell lattice showing the number of molecules of a) 6 in polymorph II, b) $6 \cdot 2 \mathrm{CH}_{2} \mathrm{Cl}_{2}{ }^{1 \text { a }}$ in polymorph $\mathrm{I}$. 


\section{F. LC-MS and FT-IR studies of the crude reaction mixture}

F1. FT-IR Data:

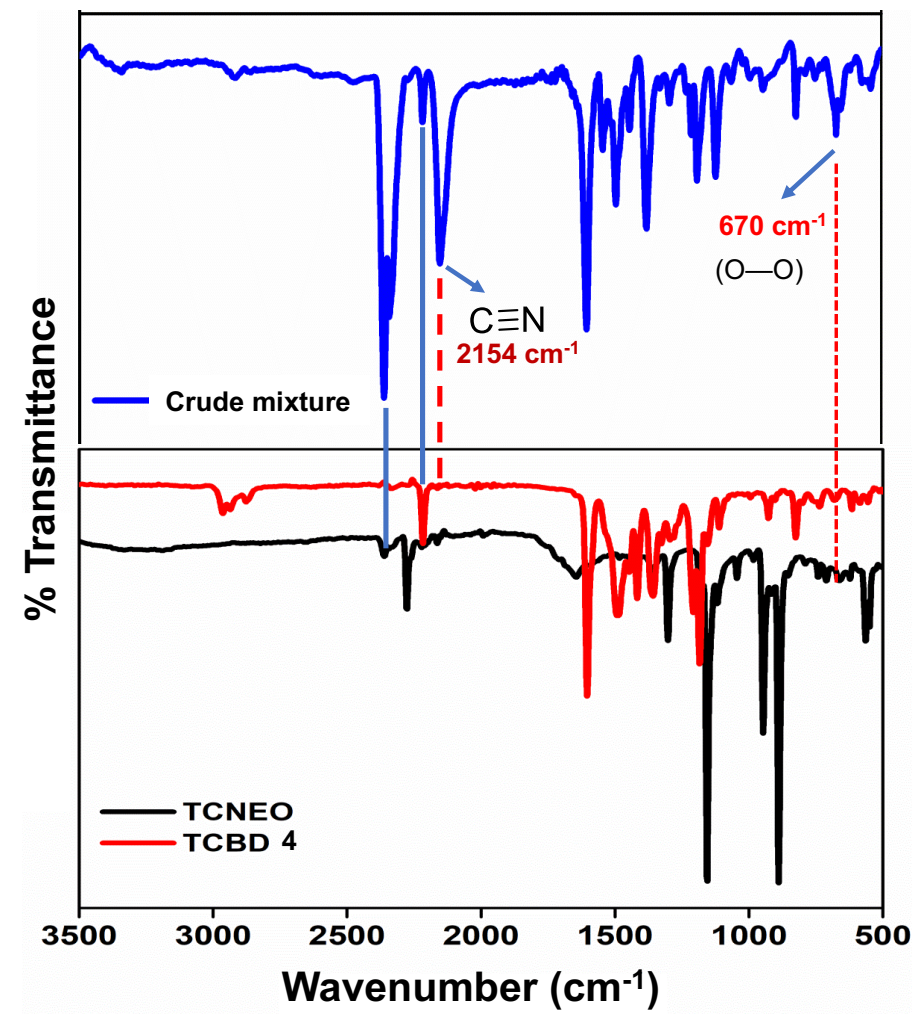

Figure S11. FT-IR (ATR) spectra of the crude reaction mixture, TCNEO, and TCBD 4.

F2. LC-MS Data:

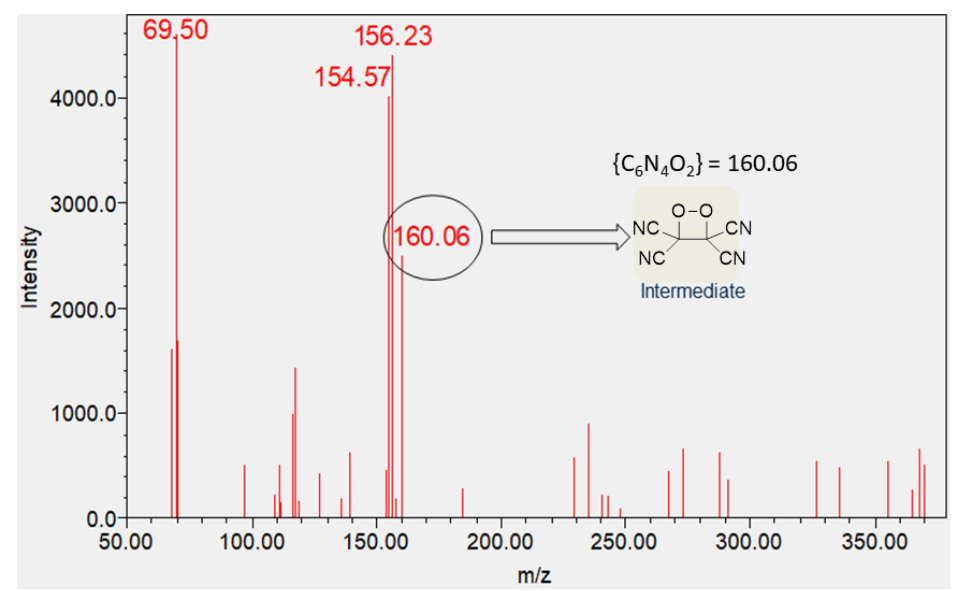

Figure S12. LC-MS spectrum of the crude reaction mixture for the 3 and TCNEO (MS-ESI) $m / z$ Calcd for $\left\{\mathrm{C}_{6} \mathrm{~N}_{4} \mathrm{O}_{2}\right\}: 160.00$, found 160.06 .

Liquid chromatography-mass spectrometry (LC-MS): The analysis of reactive intermediates is carried out by using a reverse-phase HPLC system from waters equipped with a photodiode array detector (Waters 2998) (Figure S12). 


\section{G. References}

1 (a) T. Michinobu, J. C. May, J. H. Lim, C. Boudon, J. P. Gisselbrecht, P. Seiler, M. Gross, I. Biaggio and F. Diederich, A new class of organic donor-acceptor molecules with large thirdorder optical nonlinearities, Chem. Commun. 2005, 737-739; (b) T. Michinobu, C. Boudon, J. P. Gisselbrecht, P. Seiler, B. Frank, N. N. P. Moonen, M. Gross and F. Diederich, DonorSubstituted 1,1,4,4-Tetracyanobutadienes (TCBDs): New Chromophores with Efficient Intramolecular Charge-Transfer Interactions by Atom-Economic Synthesis, Chem.-Eur. J. 2006, 12, 1889-1905.

2 B. Brieten, Y.-L. Wu, P. D. Jarowski, J.-P. Gisselbrecht, C. Boudon, M. Griesser, C. Onitsch, G. Gescheidt, W. B. Schweizer, N. Langer, C. Lennartz and F. Diederich. Donor-substituted octacyano[4]dendralenes: a new class of cyano-rich non-planar organic acceptors, Chem. Sci. 2011, 2, 88-93. 